\title{
The sustainability of ecotourism stakeholders in ecologically fragile areas: Implications for cleaner production
}

Wenke Wang, Linyun Feng, Tao Zheng and Yang Liu

The self-archived postprint version of this journal article is available at Linköping University Institutional Repository (DiVA):

http://urn.kb.se/resolve?urn=urn:nbn:se:liu:diva-172401

N.B.: When citing this work, cite the original publication.

Wang, W., Feng, L., Zheng, T., Liu, Y., (2021), The sustainability of ecotourism stakeholders in ecologically fragile areas: Implications for cleaner production, Journal of Cleaner Production, 279, 123606. https://doi.org/10.1016/j.jclepro.2020.123606

Original publication available at:

https://doi.org/10.1016/j.jclepro.2020.123606

Copyright: Elsevier

http://www.elsevier.com/

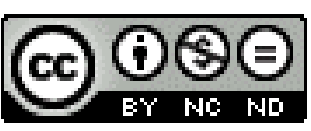




\section{Journal Pre-proof}

The sustainability of ecotourism stakeholders in ecologically fragile areas: implications for cleaner production

Wenke Wang, Linyun Feng, Tao Zheng, Yang Liu

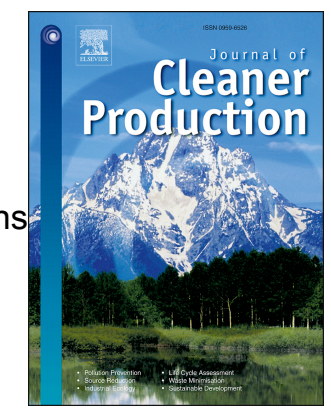

PII:

S0959-6526(20)33651-9

DOI:

https://doi.org/10.1016/j.jclepro.2020.123606

Reference: JCLP 123606

To appear in: Journal of Cleaner Production

Received Date: 23 December 2019

Revised Date: 18 June 2020

Accepted Date: 3 August 2020

Please cite this article as: Wang W, Feng L, Zheng T, Liu Y, The sustainability of ecotourism stakeholders in ecologically fragile areas: implications for cleaner production, Journal of Cleaner Production, https://doi.org/10.1016/j.jclepro.2020.123606.

This is a PDF file of an article that has undergone enhancements after acceptance, such as the addition of a cover page and metadata, and formatting for readability, but it is not yet the definitive version of record. This version will undergo additional copyediting, typesetting and review before it is published in its final form, but we are providing this version to give early visibility of the article. Please note that, during the production process, errors may be discovered which could affect the content, and all legal disclaimers that apply to the journal pertain.

(C) 2020 Published by Elsevier Ltd. 


\section{CRediT author statement}

Wenke Wang: Conceptualization, Methodology, Software.

Linyun Feng: Data curation, Writing - Original Draft.

Tao Zheng: Supervision, Visualization, Investigation, Writing - Review \& Editing.

Yang Liu: Supervision, Validation, Writing - Review \& Editing. 


\title{
The sustainability of ecotourism stakeholders in ecologically fragile zones: an evolutionary game approach
}

\author{
Wenke Wang $^{\text {a, b }}$, Linyun Feng ${ }^{\text {a }}$, Tao Zheng ${ }^{\mathrm{c}, \mathrm{d}, * *}$, Yang Liu ${ }^{\mathrm{e}, \mathrm{f}, *}$ \\ ${ }^{a}$ School of Business, Sichuan Normal University, Chengdu, China \\ ${ }^{\mathrm{b}}$ Sichuan Provincial Key Laboratory of Sci-tech Finance and Mathematical Finance, Sichuan \\ University, Chengdu, China \\ ${ }^{c}$ School of Economics and Management, Sichuan Normal University, Chengdu, China \\ ${ }^{\mathrm{d}}$ Department of Science Research, Xichang Minzu Preschool Normal College, Xichang, China \\ ${ }^{\mathrm{e}}$ Department of Management and Engineering, Linköping University, SE-581 83 Linköping, Sweden \\ ${ }^{\mathrm{f}}$ Department of Production, University of Vaasa, 65200 Vaasa, Finland \\ * Corresponding authors: zhengtao@ sicnu.edu.cn (T. Zheng), yang.liu@liu.se (Y. Liu)
}




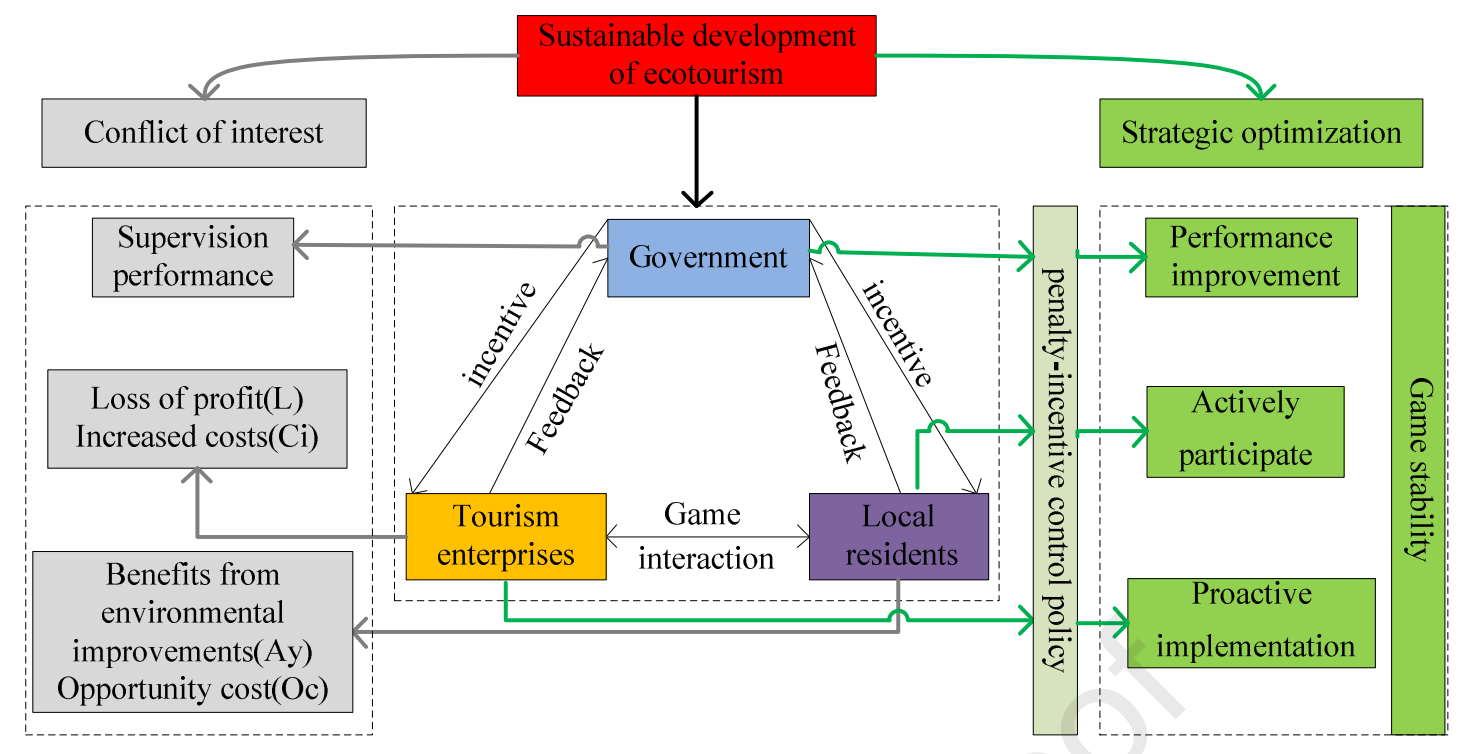




\title{
The sustainability of ecotourism stakeholders in ecologically fragile areas: implications for cleaner production
}

\author{
Wenke Wang $^{\text {a, b }}$, Linyun Feng ${ }^{\text {a }}$, Tao Zheng ${ }^{\text {c, d, } * *, ~ Y a n g ~ L i u ~}{ }^{\text {e, f, } *}$ \\ ${ }^{a}$ School of Business, Sichuan Normal University, Chengdu, China \\ ${ }^{\mathrm{b}}$ Sichuan Provincial Key Laboratory of Sci-tech Finance and Mathematical Finance, Sichuan \\ University, Chengdu, China \\ ${ }^{\mathrm{c}}$ School of Economics and Management, Sichuan Normal University, Chengdu, China \\ ${ }^{\mathrm{d}}$ Department of Science Research, Xichang Minzu Preschool Normal College, Xichang, China \\ ${ }^{\mathrm{e}}$ Department of Management and Engineering, Linköping University, SE-581 83 Linköping, Sweden \\ ${ }^{\mathrm{f}}$ Department of Production, University of Vaasa, 65200 Vaasa, Finland \\ * Corresponding authors: zhengtao@sicnu.edu.cn (T. Zheng), yang.liu@liu.se (Y. Liu)
}

\begin{abstract}
The research on ecotourism has attracted much attention in recent years with the increasing awareness of sustainable development and environmental protection. In the development and construction of ecotourism in ecologically fragile areas, however, conflicts of interest between stakeholders often negatively affect the efficiency and effectiveness of ecotourism construction. This paper applied evolutionary game theory to analyse the evolutionary stable strategies of local governments, tourism enterprises and residents in the development and construction of ecotourism in ecologically fragile areas, to explore the mechanism that influences the sustainable development policies. The evolutionary stable strategies of the game were calculated and the dynamic simulation of the model was also discussed by using a system dynamics method to analyse the stability of interaction among the stakeholders and determine an equilibrium solution. The simulation results showed that the
\end{abstract}


strategic choices of the three stakeholders fluctuate repeatedly, which indicated that there was no evolutionary stability strategy in the interaction among the current stakeholders. Therefore, an optimized dynamic penalty-incentive control method was proposed to control the fluctuation, after which the simulation results showed that the optimized dynamic penalty-incentive control method can not only effectively suppress the fluctuation but also obtain an ideal evolutionary stable strategy. Then, the cooperation mode can be changed from any original status into the desired target. This research provides valuable information for design appropriate policies and business modes to coordinate the interests of stakeholders and promote the development of ecotourism, as well as contributes to the environmental and sustainability research and practice.

Keywords: Sustainability; Ecotourism; Ecologically fragile areas; Evolutionary game theory; System dynamics; Stability control scenarios

\section{Introduction}

The ecosystems in ecologically fragile areas have weak anti-interference ability, strong temporal and spatial fluctuation, significant edge effect and poor recovery ability (Ding et al., 2018; Lu et al., 2019). For a long time, the ecosystems have been seriously damaged under the interference of human activities in many areas, such as Gansu, Qinghai and other ecologically fragile areas of China, and there is a great conflict between social and economic development and ecological environment protection in the Eastern Cape Province, South Africa (Yan et al., 2017; Yu and Wang, 2010). The protection of the ecological environment and the development of economy, which pose a great challenge to the sustainable development of the ecologically fragile areas, are particularly important and urgent (Ma et al., 2019; Qi et al., 2013; Tang et al., 2018). Then, how to coordinate the relationship between environmental protection and economic development has become a key problem of 
sustainable development in the ecologically fragile areas (Deng et al., 2016; Xie et al., 2019; Guo et al., 2018).

The development of ecotourism in ecologically fragile areas becomes the key to achieve environmental protection, local economy revitalization and sustainable development (He et al., 2018; Vidović, 2018; Zhang, 2017). Chengdu, Sichuan, took advantage of the main venue of World Tourism Day to launch Jiuzhaigou, Huanglong, Emeishan and other scenic spots, and successfully developed ecotourism products. Zhangjiajie National Forest Park in Hunan held the International Forest Protection Festival and launched Wuling Park and other ecotourism areas (Dey et al., 2018). The ecotourism of the birds-watching program at a Birdland in Seosan city promoted the development of local tourism and ecological protection (Lee and Jan, 2015). In Southern Africa, Private sector ecotourism plays an important role in job creation (Li et al., 2018; Snyman, 2017). Vigorously developing ecotourism can solve the contradiction between human and nature, acquisition and protection, realistic interests and long-term interests produced by traditional tourism in ecologically fragile areas (Lee et al., 2017; Masih et al., 2018). Ecotourism plays an important role in promoting the sustainable development of tourism, protecting the ecological environment in ecologically fragile areas, and realizing economic development, social progress and environmental optimization (Kang et al., 2018; Ocampo et al., 2018).

However, there are some significant problems in the development and construction of ecotourism in ecologically fragile areas, especially in the strategic game among the various stakeholders to maximize their respective interests (Osman et al., 2018; Tseng et al., 2019). Because of the asymmetric distribution of ecotourism resources and unbalanced regional economic development, residents and local governments often develop "ecotourism" under the banner of protecting the ecology to seek their 
interests and achievements, while secretly trampling on the natural ecological environment (Lee and Choi, 2017; Lee and Son, 2016). There is no balance between development before protection and development after protection, which may lead to further deterioration of the ecological environment (Massingham et al., 2019; Withanachchi et al., 2018). In the process of developing and constructing ecotourism, tourism enterprises will adjust their strategies according to the policies of local governments, but they may sacrifice the ecological environment in pursuit of maximizing short-term benefits (Su et al., 2014; Font et al., 2016). The strategies of tourism enterprises largely determine the implementation strategies of other stakeholders (Margaryan and Stensland, 2017). However, existing studies were surprisingly unconcerned about stakeholders conflicts of interest, especially in the ecotourism in ecologically fragile areas. Whether the existing cooperation mode and incentive policy are feasible, what the mechanism functioning is, and what impacts it will have, need to be demonstrated more comprehensively.

Therefore, it is necessary to study the stakeholders' interaction and strategic choice in the development and construction of ecotourism in ecologically fragile areas (Diamantis, 2018). In this study, the key is the interaction and game process of the local government, tourism enterprises and residents under different objectives and interests. Then, how to encourage the three stakeholders to cooperate is the main topic of this paper. Clearly, the payoffs/profits of the three populations are the main driving forces. This paper applied the evolutionary game theory to describe the interaction among local governments, tourism enterprises and residents and the evolution process of strategies was described by replicator dynamic (RD) equations (Cheng et al., 2011). Besides, the dynamic simulation of the evolutionary game model was also discussed by using the system dynamics method to analyse the stability of interaction among the stakeholders and determine an equilibrium solution in the case of 
the bounded rationality. Finally, a control method was proposed to suppress the fluctuation and an ideal evolutionarily stable strategy was obtained. This provided a theoretical basis for achieving a win-win situation among the three parties.

The rest of the paper is organised as follows. In Section 2, the literature about the stakeholders of ecotourism in recent years was reviewed. In Section 3, a game model was analysed, solved and simulated. In Section 4, the effective stability control of the model was carried out. In Section 5, results were discussed, and Section 6 concluded the paper.

\section{Literature review}

Ecology defines an ecologically fragile zone as an interface area that transits from one ecological landscape to another (Mtapuri and Giampiccoli, 2019). Ecologically fragile areas for tourism development should include ecologically fragile areas of nature and culture (Ding et al., 2018). It is pointed out that ecologically fragile areas of nature refer to areas where two different types of ecosystems transit to each other (Huang et al., 2009). The ecosystems in these areas are relatively unstable and sensitive to environmental changes and are vulnerable to degradation and succession due to the impact of external information (Yang et al., 2018). After being damaged, the ecosystems have a weak ability to self-repair and will recover for a long time or will not recover at all, and the anti-interference ability of the ecosystems themselves is weak. Besides, these areas are sensitive to global climate change, the local climate is prone to sustained drought, plant drought and biochemical phenomena are very obvious, and natural disasters are frequent (Tan et al., 2018; Wang et al., 2018). The ecosystems in these areas are instable and prone to shift on the spatial and temporal scale; regional marginal effects are significant and environmental heterogeneity is high (Liu, 2006; Peng et al., 2011).

Ecotourism is the main form of sustainable tourism (He et al., 2018; Phelan et al., 2020). Its 
concept was first proposed by the World Conservation Union in 1983 and then redefined by the International Ecotourism Society as tourism activities with dual responsibilities of protecting the natural environment and maintaining the lives of local people (Li, 2011). Ecotourism is tourism with distinctive and characteristic environments as its main landscape (Chen, 2017; Motlagh et al., 2020). It mainly refers to the tourism mode of ecological education, ecological experience and ecological cognition, which takes sustainable development as its concept, ecological environment protection as its premise, and harmonious development of human and nature as its criterion, and relies on better natural ecological environment and unique human ecological system (Hagenlocher et al., 2018; Shi et al., 2019). At present, the environmental pollution and destruction of tourist areas are serious, and all stakeholders are deeply affected by the environmental damage of tourist areas (Lee and Son, 2016). To develop sustainable tourism and promote ecological environment protection and economic development, the relationship and evolution process of major stakeholders should be mainly analysed and studied (Lee and Jan, 2018; Lee, 2019).

Because ecotourism is implemented with the participation of many stakeholders such as government, enterprises, and residents, it is a cooperative game process from contradiction and conflict, coordination and equilibrium to the ultimate realization of mutual benefit and win-win (Kan et al., 2018; Choi, 2020). Stakeholders' participation is an essential condition for the healthy development of ecotourism, and the equilibrium of interests among them is a precondition for the development of ecotourism in ecologically fragile areas (Ding and Cao, 2019). The structure of ecotourism stakeholders and their respective roles and responsibilities in ecologically fragile areas should be built based on the scope and level of them (Kuang, 2010; Ran et al., 2009). Stakeholders' interest demands are the core characteristics (Sun and Zhang, 2019). Based on carefully analysing the interest demands 
of various stakeholders in Zhalong Nature Reserve, some research put forward the ideas and plans for the co-governance of ecological tourism stakeholders (Feng and Xu, 2012). The harmony of the relationship between stakeholders directly determines the success of ecotourism. Taking Changbai Mountain, Jigong Mountain, Tianmu Mountain, Wang Lang, Jiuzhaigou and Xishuangbanna as examples, the potential contradictions among stakeholders of ecotourism, causes of conflicts and preventive measures were illustrated (Fang et al., 2012). Fei (2015) established a game model of interests among stakeholders in the process of ecotourism development and the behaviour strategies were obtained. Huang et al. (2015) established two dynamic evolutionary game models of "tourism enterprise-community" and "tourism enterprise-local governments" and got the conclusions that a public opinion mechanism should be introduced to supervise the local governments; tourism enterprises could share part of the benefits, and the cultural literacy of local residents should be improved, etc. Aliani et al. (2018) used system dynamics modelling to study the interaction among and dynamics of the main components of ecotourism in Taleghan area discussed the impact of the environment on the demand for ecotourism and concluded that environmental degradation and the decline of environmental quality led to the reduction of demand for ecotourism.

With the further development of ecotourism, the demands of stakeholders are more diverse and complex, and the contradictions will be further deepened. Therefore, more mature theoretical methods are needed to explore the internal interests to make the study closer to reality (Lonn et al., 2018; Li et al., 2020). From the perspective of evolutionary game in combination with system dynamics simulation, aiming at the local government regulation when the tourism enterprises implement ecotourism in the construction of the ecotourism zone, this paper constructs a tripartite evolutionary game model and uses system dynamics method to simulate and analyse the strategy combination of three stakeholders to 
provide long-term and stable implementation strategies for the three stakeholders in the construction of ecotourism areas.

\section{The model}

Evolutionary game theory can overcome the shortcomings of the traditional game theory in analyzing the dynamic process of bounded rationality players. The evolutionary game theory combines game theory with dynamic evolutionary process analysis, which is the evolving life form of game theory applied to population biology. In the multi-player game in developing and constructing ecotourism in ecologically fragile areas, multi-players have bounded rationality and dynamically interact. The players change the dynamic observation of strategies and benefit comparison and then adjust their strategies. Therefore, evolutionary game theory is more suitable to analyse the dynamic evolution process (Chang et al., 2017).

\subsection{Game design and description}

The development and construction of ecotourism in ecologically fragile areas need attention and participation from many aspects. Before constructing the behavioural game model among local governments, tourism enterprises and residents, we must make some assumptions which are basically in line with the current situation of the behaviours of various stakeholders in the development of ecotourism and are conducive to simplified analysis (Shi et al., 2019). To facilitate the analysis, it is assumed that the model includes three main stakeholders, i.e., local governments, tourism enterprises and residents. Local governments also include local organizations and associations that carry out environmental protection work and promulgate some relevant environmental protection laws and regulations. The tourism enterprises refer to the business units that are relatively independent and engaged in tourism economic activities under the unified leadership of the state. At the same time, it is 
assumed that the local governments, tourism enterprises and residents in the game are all to maximize their interests. Therefore, the following assumptions are made:

1. There are two kinds of behaviours of local governments in the process of game: (1) supervising in environmental and ecological management, which refers to that local governments actively resist and monitor the non-ecological behaviours of enterprises; (2) not supervising in environmental and ecological management, which refers to that local governments are not active in monitoring the implementation of ecological behaviours of enterprises, or because of costs and other reasons, ultimately chooses to let the behaviours of enterprises go or implement management only under the situation of tip-off.

2. There are two kinds of behaviours of residents in the process of game: (1) participating in environmental management, which refers to that residents resist and monitor the non-ecological behaviours of tourism enterprises by tipping-off, participating in environmental assessment and claiming for compensation, and at the same time, supervising whether the local governments supervise the tourism enterprises; (2) not participating in environmental management, wherein refers to that residents do not have the consciousness of supervising the non-ecological behaviours of enterprises, or because of costs and other reasons, ultimately choose to ignore the negligence of duty of local governments and the non-ecological behaviours of tourism enterprises.

3. Similarly, there are two kinds of behaviours of tourism enterprises in the process of the game: (1) implementing ecotourism; (2) not implementing ecotourism.

The following assumptions are made about the benefits and costs of local governments, tourism enterprises and residents under different strategies:

E: Direct economic benefit of tourism enterprises not implementing ecotourism 
$\mathrm{Ci}$ : Cost increase of tourism enterprises implementing ecotourism comparing with not implementing ecotourism

S: Local governments’ subsidy for enterprises implementing ecotourism

P: Local governments' penalty for enterprises not implementing ecotourism

L: Loss incurred to tourism enterprises not implementing ecotourism when residents don't participate

C: Supervision cost of local governments

Lr: Reputation loss of local governments not implementing supervision

Li: Loss incurred when local governments do not implement supervision and are tipped off by the public

Oc: Opportunity cost of residents participating in environmental protection

$\mathrm{R}$ : Reward from local governments to residents participating in ecotourism

Ay: Benefit from environmental improvement and cultural quality improvement when residents participate in ecotourism under the situation that tourism enterprises implement ecotourism

An: Benefit from environmental improvement and cultural quality improvement when residents participate in environmental management under the situation that tourism enterprises do not implement ecotourism

Lw: Loss caused by environmental deterioration borne by residents when tourism enterprises do not implement ecotourism

Each parameter is a constant greater than 0. Based on the above assumptions and definitions, a game tree of strategic interaction among local governments, residents and tourism enterprises can be obtained, as shown in Fig.1. 


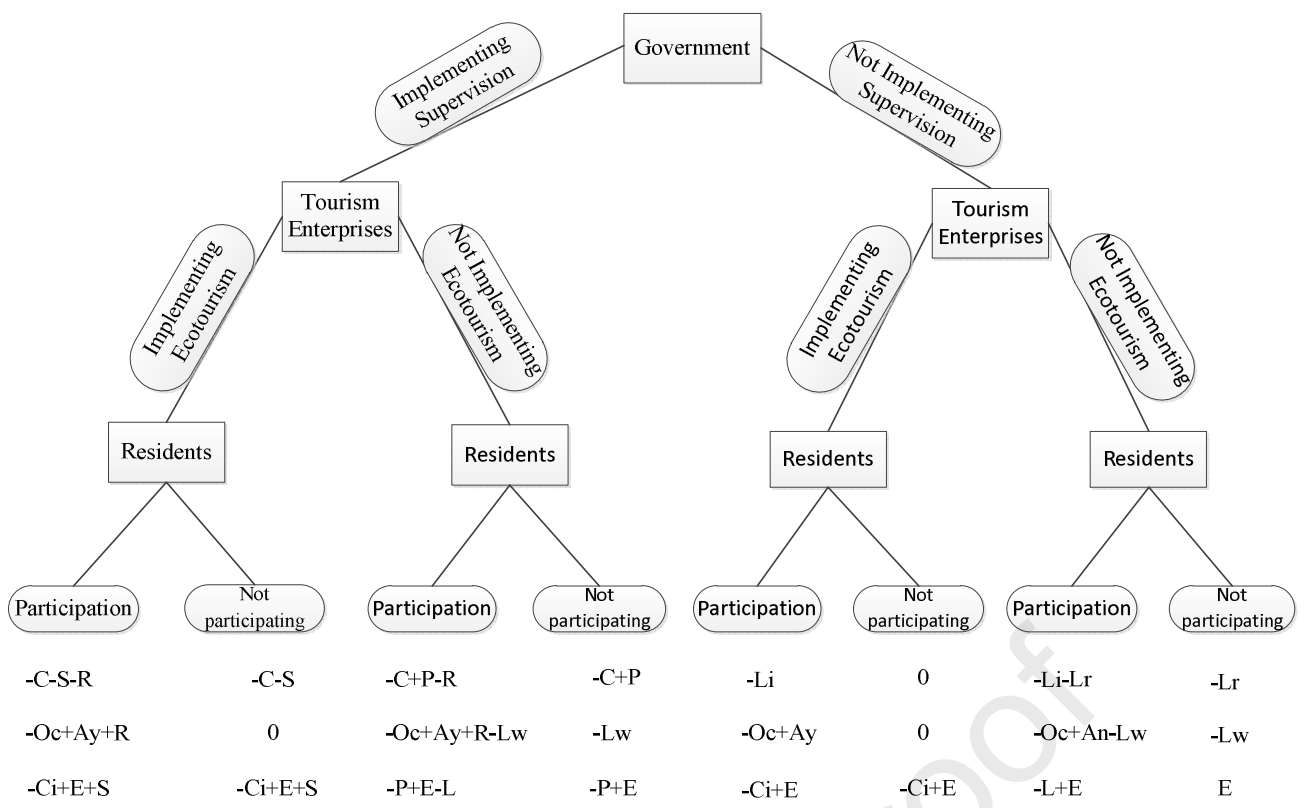

Fig. 1. Tripartite game strategy tree of local governments, residents and tourism enterprises.

\subsection{Game solution}

It is assumed that, at the initial moment, the probabilities that tourism enterprises choose the strategy of "implementing ecotourism" and "not implementing ecotourism" are $\mathrm{p}_{1}$ and 1- $\mathrm{p}_{1}$ respectively. The $\mathrm{p}_{1}$ represents the degree of the implementation and $\mathrm{p}_{1}=0$ or $=1$ means that the tourism enterprises do not implement ecotourism or have been insisting on implementing ecotourism; the probabilities that residents adopt the strategy of "participating" and " not participating" are $\mathrm{p}_{2}$ and $1-\mathrm{p}_{2}$ respectively. The $\mathrm{p}_{2}$ reflects the degree of participation of residents; the probability that local governments adopt the strategy of "supervising" and "not supervising" are $p_{3}$ and $1-p_{3}$ respectively. similarly, $p_{3}$ represents the degree of supervision of the local governments, where the range of $\mathrm{p}_{1}, \mathrm{p}_{2}$ and $\mathrm{p}_{3}$ is $[0,1]$.

The expected benefit when the local governments implement supervision is $U_{1}$ (Equation (1)), the expected benefit when the local governments do not implement supervision is $U_{2}$ (Equation (2)), and the average benefit of the local governments is $U$ (Equation (3)), so:

$$
\begin{aligned}
& U_{1}=-p_{1}(S+P)-p_{2} R-C+P \\
& U_{2}=p_{1} L r-p_{2} L i-L r
\end{aligned}
$$




$$
U=p_{3} U_{1}+\left(1-p_{3}\right) U_{2}
$$

It is assumed that the time is continuous, and the local government tends to imitate and learn game strategies with high returns, more specifically, in a given current behaviour distribution, the greater the benefit and return of a strategy, the more it is imitated and learned(Liu and Li, 2015). According to the theory and thought of imitating dynamics in evolutionary game, if at a certain moment the ratio of supervision implemented by the local government is $\mathrm{p}_{3}$, then the change rate of supervision ratio at the next moment is related to the current ratio of supervision and the gap between the pure strategy expected benefit and the average benefit of supervision, that is, the change rate of supervision ratio is established as Equation (4):

$$
\mathrm{d} p_{3} / d t=p_{3}\left(U_{1}-U\right)=p_{3}\left(1-p_{3}\right)\left[-p_{1}(S+P+L r)-p_{2}(R-L \mathrm{i})-C+P+L \mathrm{r}\right]
$$

Similarly, the change rates of strategic choices of the tourism enterprise and residents can be obtained as Equation (5) and (6) respectively:

$$
\begin{gathered}
\mathrm{d} p_{1} / d t=p_{1}\left(1-p_{1}\right)\left[p_{2} L+p_{3}(S+P)-C i\right] \\
\mathrm{d} p_{2} / d t=p_{2}\left(1-p_{2}\right)\left[p_{1}(A y-A n)+p_{3}(A y-A n+R)-p_{1} p_{3}(A y-A n)-O c+A n\right]
\end{gathered}
$$

The above Equations (4) (5) (6) describe the replicator dynamic equations of multi-players interaction game in the development and construction of ecotourism in the whole ecologically fragile zone, and constitute the following equation set:

$$
\left\{\begin{array}{l}
\mathrm{d} p_{1} / d t=p_{1}\left(1-p_{1}\right)\left[p_{2} L+p_{3}(S+P)-C i\right] \\
\mathrm{d} p_{2} / d t=p_{2}\left(1-p_{2}\right)\left[p_{1}(A y-A n)+p_{3}(A y-A n+R)-p_{1} p_{3}(A y-A n)-O c+A n\right] \\
\mathrm{d} p_{3} / d t=p_{3}\left(1-p_{3}\right)\left[-p_{1}(S+P+L r)-p_{2}(R-L \mathrm{i})-C+P+L \mathrm{r}\right]
\end{array}\right.
$$

The above replicator dynamic equation set (7) reflects the speed and direction of strategic adjustment of tourism enterprises, residents and local governments. When it equals zero, it indicates that the speed of strategy adjustment equals zero and the evolutionary game system reaches a relatively stable equilibrium state. 
Therefore, the computer simulation can be applied to obtain better decision-making support. By modelling and dynamic analysis of the multi-player evolutionary game process of development and construction of ecotourism in ecologically fragile areas, we can achieve the purpose of analyzing the stability of all equilibrium points of the replicator dynamic equation of the system.

\subsection{Game analysis based on system dynamics}

In the group evolutionary game model, individuals use replicator dynamics to describe their learning evolution mechanism. By observing and comparing their benefits with those of other individuals in the same group, they can imitate and learn, to adjust their strategic choices. Therefore, system dynamics can be used to study the stability of equilibrium solution and to analyse the feedback mechanism of multi-player game in the development and construction of ecotourism in ecologically fragile areas(Liu et al., 2015; Wu et al., 2013). Besides, according to the above assumptions and analysis for the game, the game system is composed of three subsystems, i.e., local governments, residents and tourism enterprises. An SD model of the evolutionary game is established by Vensim PLE 6.0, as shown in Fig.2. The functional relationships among state variables, flow rate variables and intermediate variables in the model are determined according to the replicator dynamic equations of multi-player evolutionary game of development and construction of ecotourism in ecologically fragile areas. 


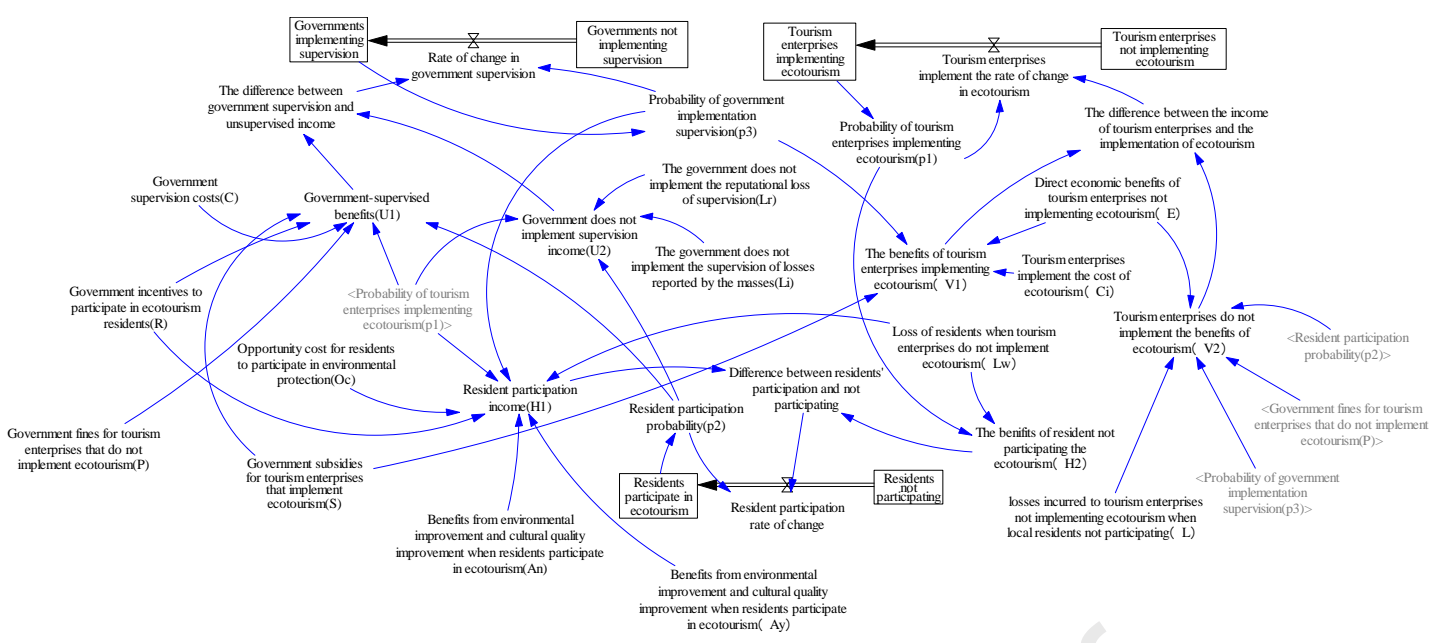

Fig. 2. Evolutionary game SD model for eco-behaviour supervision of tourism enterprises.

According to the functional relationships, level variables, rate variables and auxiliary variables between game systems are set in the above replicator dynamic Equation (7). The data are obtained according to the investigations by related experts and the related literature in the field of ecotourism (Peng et al., 2017; Ye et al., 2018), and the relevant data of the SD model in this research are set as follows: INITIAL TIME $=0$, FINAL TIME $=1000$, TIME STEP $=1$, Units for Time is set to Day, and the initial values of external variables of the SD model are shown in Table 1 after pre-treatment.

Table 1. Initial simulation parameters

\begin{tabular}{llllllllllllll}
\hline Variable & $\mathrm{E}$ & $\mathrm{Ci}$ & $\mathrm{S}$ & $\mathrm{P}$ & $\mathrm{L}$ & $\mathrm{C}$ & $\mathrm{Lr}$ & $\mathrm{Li}$ & $\mathrm{Oc}$ & $\mathrm{R}$ & $\mathrm{Ay}$ & $\mathrm{An}$ & $\mathrm{Lw}$ \\
\hline Value & 10 & 4 & 10 & 4 & 1 & 1 & 2 & 6 & 3 & 2 & 3 & 2 & 2 \\
\hline
\end{tabular}

The value of each external variable is substituted into the multi-player game replicator dynamic equation for the development and construction of ecotourism in ecologically fragile areas and solved. Therefore, the equilibrium strategy combination of the evolutionary dynamic equation set (7) of the multi-player game group is obtained, that is, eight pure strategy equilibrium points $\mathrm{X}_{1}-\mathrm{X}_{8}$ and two mixed strategy equilibrium points $\mathrm{X}_{9}$ and $\mathrm{X}_{10}$ are obtained as Equation (8). 


$$
\begin{aligned}
& X_{1}=\left[\begin{array}{l}
0 \\
0 \\
0
\end{array}\right], X_{2}=\left[\begin{array}{l}
0 \\
1 \\
0
\end{array}\right], X_{3}=\left[\begin{array}{l}
0 \\
1 \\
1
\end{array}\right], X_{4}=\left[\begin{array}{l}
0 \\
0 \\
1
\end{array}\right], X_{5}=\left[\begin{array}{l}
1 \\
0 \\
0
\end{array}\right], X_{6}=\left[\begin{array}{l}
1 \\
1 \\
0
\end{array}\right], X_{7}=\left[\begin{array}{l}
1 \\
0 \\
1
\end{array}\right], X_{8}=\left[\begin{array}{l}
1 \\
1 \\
1
\end{array}\right] \\
& X_{9}=\left[\begin{array}{c}
5 / 16 \\
0 \\
2 / 7
\end{array}\right], \quad X_{10}=\left[\begin{array}{c}
9 / 16 \\
1 \\
3 / 14
\end{array}\right]
\end{aligned}
$$

Taking $\mathrm{X}_{9}$ as an example, $\mathrm{X}_{9}$ is substituted into the SD model of evolutionary game to simulate, and the evolutionary game state at this equilibrium point is obtained. As shown in Fig. 3, it is found that, at the initial mixed strategy equilibrium point $\mathrm{X}_{9}$, the three parties of the game do not actively change their initial strategies, and no player in each group adopts new strategies. At this time, the game is in a relative equilibrium state. Similarly, the simulation results show that at the mixed strategy equilibrium point $\mathrm{X}_{10}$ and other pure strategy equilibrium points $\mathrm{X}_{1}-\mathrm{X}_{8}$, the three parties of the game have not actively changed their initial strategies. However, the states of these equilibrium points are unstable and path-dependent. For example, at the initial mixed strategy equilibrium point $\mathrm{X}_{9}$, if a small number of individuals in the resident population mutate, the participation ratio of residents mutates from $\mathrm{p}_{2}=0$ to $\mathrm{p}_{2}=0.1$. This state is simulated and the simulation results are as shown in Fig. 4 .

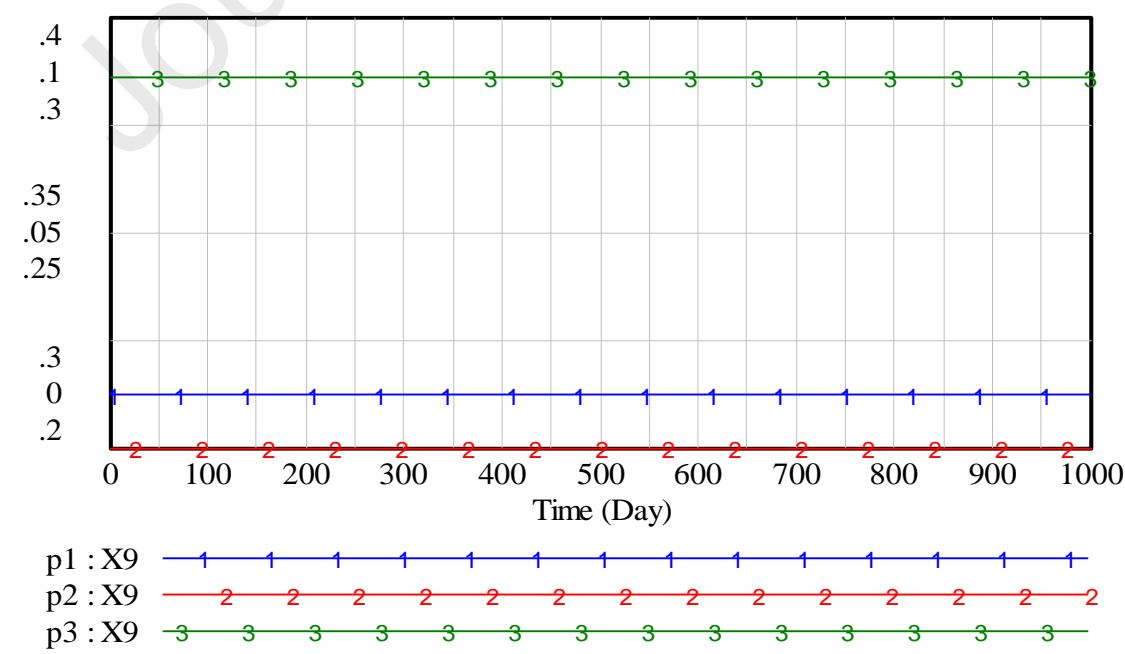

Fig. 3. The game evolution process of initial mixed strategy $X_{9}$. 


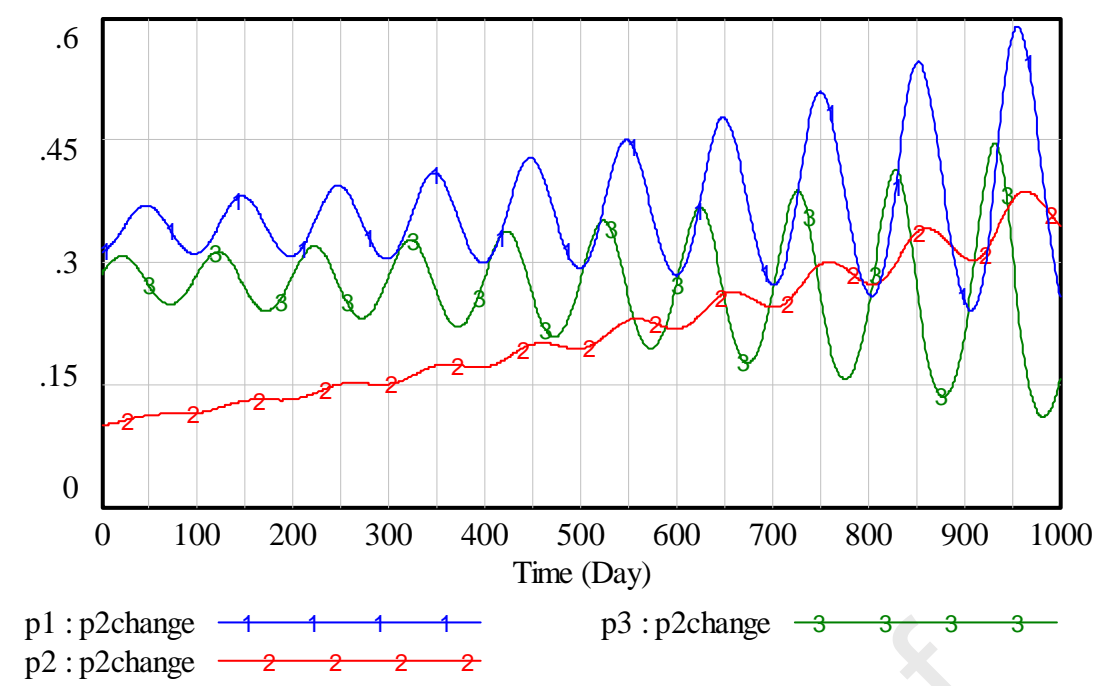

Fig. 4. The game evolution process of mutation of initial mixed strategy $\mathrm{X}_{9}$.

The simulation results show that the equilibrium state of the mixed strategy equilibrium point $\mathrm{X}_{9}$ is unstable, and the resident population will evolve to $\mathrm{p}_{2}=1$. Similarly, the equilibrium states of the mixed strategy equilibrium point $\mathrm{X}_{10}$ and other pure strategy equilibrium points $\mathrm{X}_{1}-\mathrm{X}_{8}$ are also unstable. To sum up, SD is used to study the feedback mechanism of the multi-player game in the development and construction of ecotourism in ecologically fragile areas. The evolutionary game process is modelled and the stability of equilibrium strategy points is analysed. It is found that there is a trend of repeated fluctuation and shock in the game process, which indicates that there is no evolutionarily stable strategy in the game process. (Wang et al., 2011).

\subsection{Stability analysis and check}

To verify the simulation results, the initial values given to the system parameters are shown in Table 1 and the game model was solved and the equilibrium solutions were verified. According to the above-mentioned three-party evolutionary game model replicated dynamic equation set (7) and the initial values of the parameters, the eight pure strategy equilibrium points $\mathrm{X}_{1}-\mathrm{X}_{8}$ and two mixed strategy equilibrium points $\mathrm{X}_{9}$ and $\mathrm{X}_{10}$ are obtained as Equation (8). Then, the stability of the

$$
J=\left[\begin{array}{ccc}
-p_{1}\left(p_{2}+14 p_{3}-4\right)- & -p_{1}\left(p_{1}-1\right) & -14 p_{1}\left(p_{1}-1\right) \\
\left(p_{1}-1\right)\left(p_{2}+14 p_{3}-4\right) & -\left(p_{2}-1\right)\left(p_{1}+3 p_{3}-p_{1} p_{3}-1\right) & \\
p_{2}\left(p_{2}-1\right)\left(p_{3}-1\right) & -p_{2}\left(p_{1}+3 p_{3}-p_{1} p_{3}-1\right) & p_{2}\left(p_{2}-1\right)\left(p_{1}-3\right) \\
& -4 p_{3}\left(p_{3}-1\right) & -\left(p_{3}-1\right)\left(4 p_{2}-16 p_{1}+5\right) \\
16 p_{3}\left(p_{3}-1\right) & & -p_{3}\left(4 p_{2}-16 p_{1}+5\right)
\end{array}\right]
$$


equilibrium solution can be obtained by analyzing the determinant and trace of the Jacobian matrix.

The Jacobian matrix of the game system is established as Equation (9).

The following sections use numerical analysis to discuss the evolutionary stability of each equilibrium point. Friedman proposed a method to obtain the stability of the equilibrium solution of the system's replicator dynamics equations by analyzing the Jacobian matrix and the characteristic values of the game model (Friedman, 1991). Besides, the stability of equilibrium point of replicator dynamic equation could be judged by analyzing the determinants and trace of the Jacobian matrix of the game system, that is, whether there is an evolutionarily stable strategy in the game(Jiang et al., 2019; Liu and Li, 2015; Sheng et al., 2020). According to the Lyapunov stability theory, if all characteristic values have nonpositive real parts, the system is stable; otherwise, the system is unstable.

The equilibrium solutions $\left(\mathrm{X}_{1}-\mathrm{X}_{10}\right)$ were put into the Jacobian matrix and solved to get their characteristic values. The characteristic value of each equilibrium point and the stability judgment result of each equilibrium point can be obtained. The judgment results of all equilibrium points are shown in Table 2.

Table 2. The stability analysis of equilibrium points

\begin{tabular}{ccc}
\hline Local Equilibrium Point & Characteristic Values & State \\
\hline$X_{1}=(0,0,0)$ & $(-4,-1,5)$ & saddle point \\
$X_{2}=(0,1,0)$ & $(-3,1,9)$ & saddle point \\
$X_{3}=(0,1,1)$ & $(-9,-2,11)$ & saddle point \\
\hline
\end{tabular}




\begin{tabular}{lcr}
\hline $\mathrm{X}_{4}=(0,0,1)$ & $(-5,2,10)$ & saddle point \\
$\mathrm{X}_{5}=(1,0,0)$ & $(-11,0,4)$ & saddle point \\
$\mathrm{X}_{6}=(1,1,0)$ & $(-7,0,3)$ & saddle point \\
$\mathrm{X}_{7}=(1,0,1)$ & $(-10,2,11)$ & saddle point \\
$\mathrm{X}_{8}=(1,1,1)$ & $(-11,-2,7)$ & saddle point \\
$\mathrm{X}_{9}=(5 / 16,0,2 / 7)$ & $(0.0000+3.1339 \mathrm{i}, 0.0000-3.1339 \mathrm{i}$, & saddle point \\
& $0.0804+0.0000 \mathrm{i})$ & \\
$\mathrm{X}_{10}=(9 / 16,1,3 / 14)$ & $(0.0000+3.0465 \mathrm{i}, 0.0000-3.0465 \mathrm{i}$, & saddle point \\
& $-0.0848+0.0000 \mathrm{i})$ & \\
\hline
\end{tabular}

It turned out that the characteristic value which is greater than zero appeared in each Jacobian matrix. The results show that the equilibrium state of the equilibrium solutions $X_{1}-X_{10}$ is unstable, which was consistent with the above SD simulated results.

\section{Stability control analysis}

\subsection{Stability analysis and check under the optimal dynamic penalty-incentive}

\section{control scenario}

To reach a steady-state, a dynamic penalty-incentive measure is proposed, that is, the local governments give dynamic penalties and incentives according to the information about the tourism enterprises, as shown in Equation (10) (Liu et al., 2015; Liu and Li, 2015; Chang et al., 2017).

$$
\begin{aligned}
& P a_{2}=a_{11} P\left(1-p_{1}\right)+a_{22} C i / p_{3} \\
& S b_{2}=b_{11} S p_{1}+b_{22} p_{3} / C i
\end{aligned}
$$

where $a_{11}, a_{22}, b_{11}$ and $b_{22}$ represent the corresponding penalty coefficients and incentive coefficients, which are all set to 1 to simplify the study. From this game SD model (Fig.2), optimization is performed through the dynamic penalty and incentive control scheme, and the results are as shown in 
Fig.5. When the initial strategies of three parties of the game are $\left(\mathrm{p}_{1}=0.5, \mathrm{p}_{2}=0.5, \mathrm{p}_{3}=0.5\right)$ and $\left(\mathrm{p}_{1}=\right.$ $\left.0.2, \mathrm{p}_{2}=0.1, \mathrm{p}_{3}=0.4\right)$, the evolutionary game between tourism enterprises, local residents and local governments under dynamic penalty-incentive measures is simulated. The simulation results are as shown in Fig. 6 and Fig. 7.

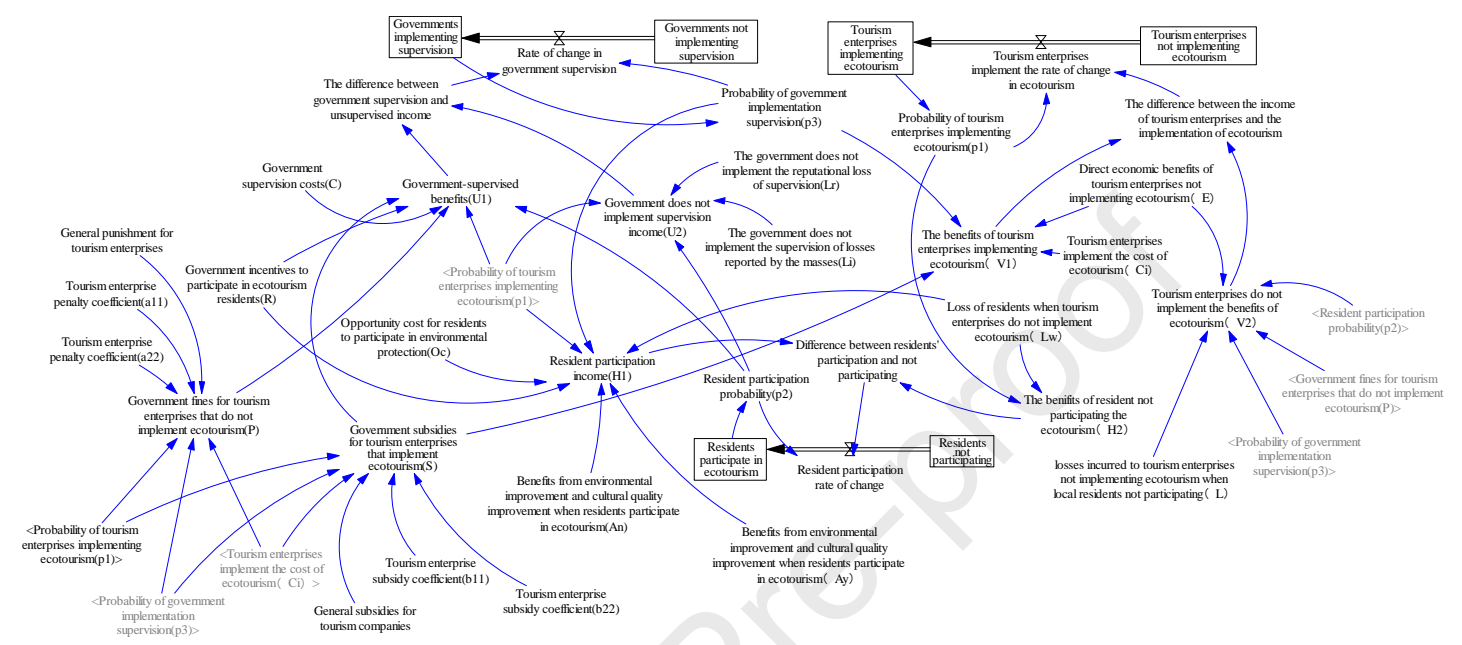

Fig. 5. Evolutionary game SD model of tourism enterprise behaviour supervision under dynamic penalty and incentive control.

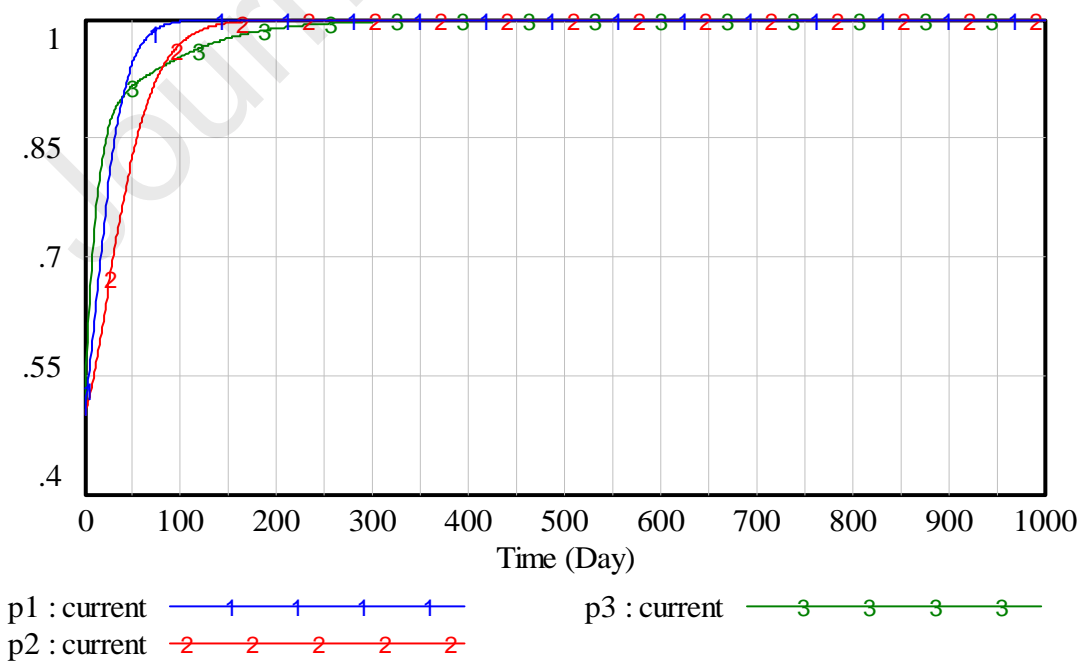

Fig. 6. Game evolution process of initial strategy $\left(\mathrm{p}_{1}=0.5, \mathrm{p}_{2}=0.5, \mathrm{p}_{3}=0.5\right)$. 


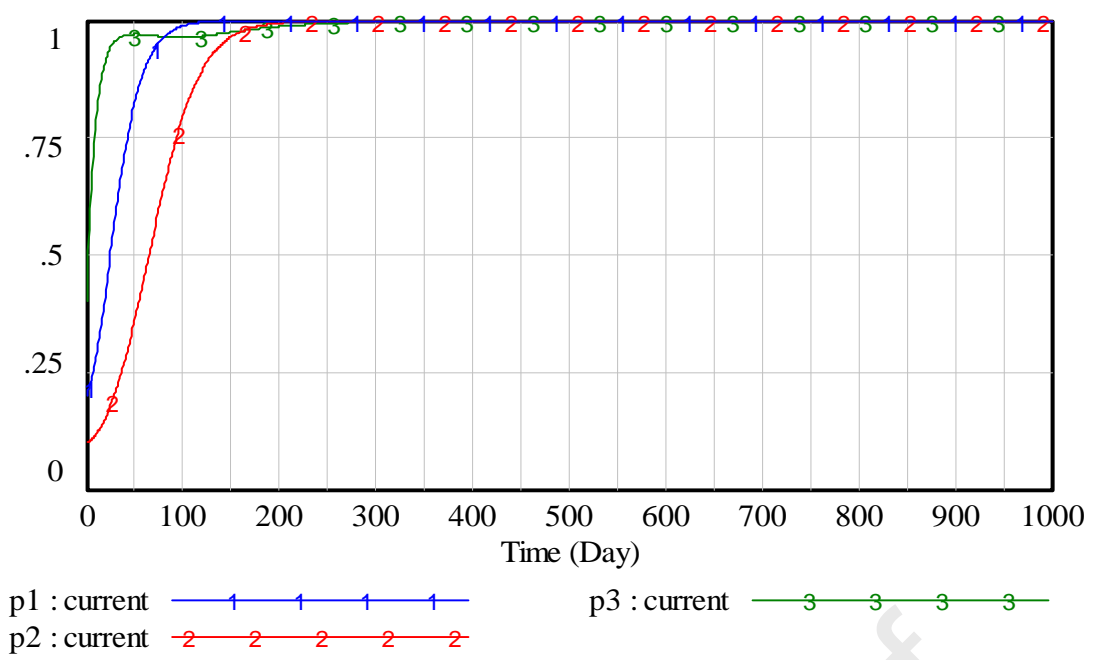

Fig. 7. Game evolution process of initial strategy $\left(\mathrm{p}_{1}=0.2, \mathrm{p}_{2}=0.1, \mathrm{p}_{3}=0.4\right)$.

From the simulation results, it can be seen that, under the dynamic penalty-incentive measures, the game evolution process approximately converges to the vicinity of $\mathrm{X}^{*}(1,1,1)^{T}$, which fully indicates that the dynamic penalty-incentive control scheme optimizes the system, and not only can effectively suppress the fluctuation, but also provides an ideal evolutionarily stable strategy. That is, in the situation of dynamic penalty-incentive, the tourism enterprises will almost choose to implement ecotourism, the residents will almost choose to participate in environmental management and the local governments will almost choose to supervise in environmental and ecological management as their optimal strategies respectively.

\subsection{Stability analysis and check under the optimal dynamic penalty-incentive scenario}

Whether the evolutionarily stable strategy under this measure is the real stable equilibrium point of the system remains to be proved. Therefore, to verify the simulation results, it is necessary to solve the evolutionary game model of the system under this measure and prove the stability of its equilibrium points to verify the validity of the simulation results of the evolutionary game.

After adding penalty-incentive measures, the initial values assigned to the parameters of the system are shown in Table 3 and the game model was solved. The three-party evolutionary game 
replicated dynamic equation are illustrated in Equation set (11).

Table 3. Simulation parameters after the change

\begin{tabular}{lllllllllllllll}
\hline Variable & $\mathrm{E}$ & $\mathrm{Ci}$ & $\mathrm{S}$ & $\mathrm{P}$ & $\mathrm{L}$ & $\mathrm{C}$ & $\mathrm{Lr}$ & $\mathrm{Li}$ & $\mathrm{Oc}$ & $\mathrm{R}$ & $\mathrm{Ay}$ & $\mathrm{An}$ & $\mathrm{Lw}$ \\
\hline Value & 10 & 4 & $\mathrm{Sb}_{2}$ & $\mathrm{~Pa}_{2}$ & 1 & 1 & 2 & 6 & 3 & 2 & 3 & 2 & 2 \\
\hline
\end{tabular}

$$
\left\{\begin{array}{l}
\mathrm{d} p_{1} / d t=p_{1}\left(1-p_{1}\right)\left[p_{2} L+p_{3}\left(S b_{2}+P a_{2}\right)-C i\right] \\
\mathrm{d} p_{2} / d t=p_{2}\left(1-p_{2}\right)\left[p_{1}(A y-A n)+p_{3}(A y-A n+R)-p_{1} p_{3}(A y-A n)-O c+A n\right] \\
\mathrm{d} p_{3} / d t=p_{3}\left(1-p_{3}\right)\left[-p_{1}\left(S b_{2}+P a_{2}+L r\right)-p_{2}(R-L \mathrm{i})-C+P a_{2}+L r\right]
\end{array}\right.
$$

According to the initial values of the parameters and the three-party evolutionary game model replicated dynamic equation, the eight pure strategy equilibrium points $\mathrm{X}_{1}-\mathrm{X}_{8}$ are obtained as Equation (12).

$$
X_{1}=\left[\begin{array}{l}
0 \\
0 \\
p_{3}
\end{array}\right], X_{2}=\left[\begin{array}{l}
0 \\
1 \\
p_{3}
\end{array}\right], X_{3}=\left[\begin{array}{l}
0 \\
1 \\
1
\end{array}\right], X_{4}=\left[\begin{array}{l}
0 \\
0 \\
1
\end{array}\right], X_{5}=\left[\begin{array}{c}
1 \\
0 \\
p_{3}
\end{array}\right], X_{6}=\left[\begin{array}{c}
1 \\
1 \\
p_{3}
\end{array}\right], X_{7}=\left[\begin{array}{l}
1 \\
0 \\
1
\end{array}\right], X_{8}=\left[\begin{array}{l}
1 \\
1 \\
1
\end{array}\right]
$$

Because the dynamic equation under the dynamic penalty-incentive measures contains $4 / \mathrm{p}_{3}, \mathrm{p}_{3}=0$ is not established. Then, the equilibrium points $\mathrm{X}_{1}, \mathrm{X}_{2}, \mathrm{X}_{5}$, and $\mathrm{X}_{6}$ were expressed with $\mathrm{p}_{3}$ instead of 0 . Then, the stability of the equilibrium solution can be obtained by analyzing the determinant and trace of the Jacobian matrix. The Jacobian matrix of the game system is established as Equation (13).

$$
J=\left[\begin{array}{ccc}
-p_{1}\left[\begin{array}{l}
p_{2}+p_{3}\left(6 p_{1}+p_{3} / 4\right. \\
\left.+4 / p_{3}+4\right)-4
\end{array}\right] & \\
-\left(p_{1}-1\right)\left[\begin{array}{l}
p_{2}+p_{3}\left(6 p_{1}+p_{3} / 4\right. \\
\left.+4 / p_{3}+4\right)-4
\end{array}\right] & -p_{1}\left(p_{1}-1\right) & {\left[\begin{array}{l}
6 p_{1}+p_{3} / 4-p_{3}\left(4 / p_{3}^{2}\right. \\
-1 / 4)+4 / p_{3}+4
\end{array}\right]} \\
-6 p_{1} p_{3}\left(p_{1}-1\right) & & \\
p_{2}\left(p_{2}-1\right)\left(p_{3}-1\right) & -\left(p_{2}-1\right)\left(p_{1}+3 p_{3}-p_{1} p_{3}-1\right) & p_{2}\left(p_{2}-1\right)\left(p_{1}-3\right) \\
& -p_{2}\left(p_{1}+3 p_{3}-p_{1} p_{3}-1\right) & -\left(p_{3}-1\right)\left[\begin{array}{l}
4 p_{2}-4 p_{1}+4 / p_{3}-p_{1} \\
\left(6 p_{1}+p_{3} / 4+4 / p_{3}+6\right)+5
\end{array}\right] \\
p_{3}\left(p_{3}-1\right)\left(12 p_{1}+p_{3} / 4+4 / p_{3}+10\right) & -4 p_{3}\left(p_{3}-1\right) & -p_{3}\left[\begin{array}{l}
4 p_{2}-4 p_{1}+4 / p_{3}-p_{1} \\
\left(6 p_{1}+p_{3} / 4+4 / p_{3}+6\right)+5
\end{array}\right] \\
& & -p_{3}\left(p_{3}-1\right)\left[p_{1}\left(4 / p_{3}^{2}-1 / 4\right)-4 / p_{3}^{2}\right]
\end{array}\right]
$$


The characteristic value of each equilibrium point and the stability judgment result of each equilibrium point can be obtained. Besides, the stability of equilibrium point of replicator dynamic equation could be judged by analyzing the determinants and trace of the Jacobian matrix of the game system, that is, whether there is an evolutionarily stable strategy in the game (Chang et al., 2017; Fang et al., 2019; Li et al., 2019). According to the Lyapunov stability theory, if all characteristic values have nonpositive real parts, the system is stable; otherwise, the system is unstable. The equilibrium solutions $\left(\mathrm{X}_{1}-\mathrm{X}_{8}\right)$ were put into the Jacobian matrix and solved to get their characteristic values. The characteristic value of each equilibrium point and the stability judgment result of each equilibrium point can be obtained. The judgment results of all equilibrium points are shown in Table 4 .

Table 4. The stability analysis of equilibrium points

\begin{tabular}{ccc}
\hline Local Equilibrium Point & Characteristic Values & State \\
\hline $\mathrm{X}_{1}=\left(0,0, \mathrm{p}_{3}\right)$ & $(0,0.4025,-0.7000)$ & saddle point \\
$\mathrm{X}_{2}=\left(0,1, \mathrm{p}_{3}\right)$ & $(3.2000,1.4025,0.7000)$ & saddle point \\
$\mathrm{X}_{3}=(0,1,1)$ & $(-13.0000,-2.0000,5.2500)$ & saddle point \\
$\mathrm{X}_{4}=(0,0,1)$ & $(-9.0000,2.0000,4.2500)$ & saddle point \\
$\mathrm{X}_{5}=\left(1,0, \mathrm{p}_{3}\right)$ & $(-8.8425,-1.0025,0.2000)$ & saddle point \\
$\mathrm{X}_{6}=\left(1,1, \mathrm{p}_{3}\right)$ & $(-11.2500,-2.0000,7.2500)$ & saddle point \\
$\mathrm{X}_{7}=(1,0,1)$ & $(-10.2500,2.0000,11.2500)$ & saddle point \\
$\mathrm{X}_{8}=(1,1,1)$ & $(-5.6425,-2.0025,-0.2000)$ & ESS \\
\hline
\end{tabular}

As the value of $\mathrm{p}_{3}$ approaches to 0 and the characteristic values have nonpositive real parts, it can be seen that the equilibrium point $\mathrm{X}^{*}(1,1,1)^{T}$ is an evolutionarily stable strategy. As can be seen from Table 4, the state of $\mathrm{X}_{8}$ is ESS, and the remaining points are saddle points. Therefore, the analysis 
consistent with the above SD simulation results $\mathrm{X}^{*}(1,1,1)^{T}$.

Accordingly, it can be seen that the application of system dynamics to simulate the evolutionary game process is an effective method to solve the stability of an equilibrium solution. Besides, optimizing the dynamic penalty-incentive control scheme can effectively suppress the existing game, stabilize the fluctuation of the game and provide an ideal evolutionarily stable strategy. The tourism enterprises will almost implement ecotourism as their optimal strategies.

\subsection{The impact of selecting an initial change of strategy on evolutionary results}

Under the conditions of the above initial setting, when the initial values of $\mathrm{p}_{2}$ and $\mathrm{p}_{3}$ are mixed strategy Nash equilibrium values, the initial value of $p_{1}$ is randomly selected to verify the effect on its evolutionary trend, as illustrated in Fig.8(a). Under the premises that meet the above-mentioned evolutionary conditions, the initial value of $\mathrm{p}_{1}$ gradually increases, and the easier it is to achieve the ideal steady-state. This shows that the stronger the willingness of tourism enterprises to implement ecotourism, the easier it is to develop and construct ecotourism in ecologically fragile areas.

Similarly, under the conditions of the above initial setting, when the initial values of $p_{1}$ and $p_{3}$ are mixed strategy Nash equilibrium values, the initial value of $\mathrm{p}_{2}$ is randomly selected to verify the effect on its evolutionary trend, as illustrated in Fig.8(b). Under the premises that meet the above-mentioned evolutionary conditions, the initial value of $\mathrm{p}_{2}$ gradually increases, and the easier it is to achieve the ideal steady-state. This means that residents can choose their "participating" strategy to maximize their interests.

Finally, verify the effect of the initial value of $\mathrm{p}_{3}$ on its evolutionary trend, and the result is similar to $\mathrm{p}_{1}$ and $\mathrm{p}_{2}$, as illustrated in Fig.8(c). The initial value of $\mathrm{p}_{3}$ is gradually increased, and the easier it is to achieve the ideal steady-state. This means that the government will choose the "supervising" strategy to 
stabilize the entire system.

In summary, it can be seen from Fig. 8 that the evolutionary results are affected by the initial probability of each stakeholders' choice. That is to say, the strategy evolution path of ecotourism between each stakeholder has a reliable degree of interdependence.

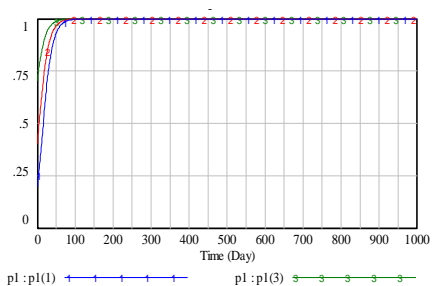
$\mathrm{pl}: \mathrm{pl}(1)$
$\mathrm{pl}: \mathrm{p}(2)$

(a) $\mathrm{p}_{1}(1)=0.2, \mathrm{p}_{1}(3)=0.4$

$\mathrm{p}_{1}(2)=0.7$

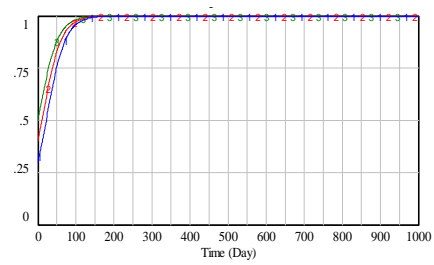

$\mathrm{p} 2: \mathrm{p} 2(1)$
$\mathrm{p} 2: \mathrm{p} 2(2)$

(b) $\mathrm{p}_{2}(1)=0.3, \mathrm{p}_{2}(3)=0.4$

$\mathrm{p}_{2}(2)=0.5$

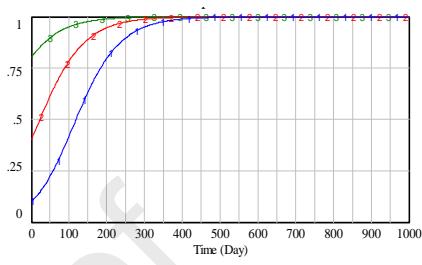

$\mathrm{p} ; \mathrm{p}: \mathrm{p} 3(1)$

(c) $\mathrm{p}_{3}(1)=0.1, \mathrm{p}_{3}(3)=0.4$

$$
\mathrm{p}_{3}(2)=0.8
$$

Fig. 8. The impact of selecting an initial change of strategy on the evolutionary results.

\subsection{The impact of parameter changes on evolutionary results}

(1) The impact of parameter changes on the strategy of tourism enterprises

When the tourism enterprise does not implement ecotourism and the residents do not participate in environmental management, the greater the value of the loss L suffered by the enterprise, the larger the value of $\mathrm{p}_{1}$, as shown in Fig.9(a). This shows that the greater the losses suffered by tourism companies, the greater the possibility of enterprises implementing ecotourism.

Generally, compared with not implementing ecotourism, the greater the cost of implementing ecotourism, the lower the willingness of tourism enterprises to implement ecotourism. As shown in Fig.9(b), let $\mathrm{Ci}=12, \mathrm{Ci}=8, \mathrm{Ci}=4$, and when $\mathrm{Ci}$ is reduced from 12 to 4 , curve 1 is converted to curve 3. That is, the smaller the $\mathrm{Ci}$, the more the tourism enterprises tend to choose the strategy of implementing ecotourism. 


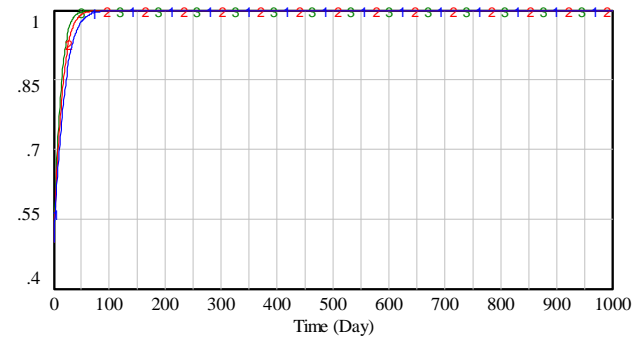

$\begin{array}{lllllll}\mathrm{p} 1: \mathrm{L}=1 & 1 & 1 & 1 & 1 & 1 \\ \mathrm{p} 1: \mathrm{L}=2 & \mathrm{C}_{2} & 2 & 2 & 2 & 2\end{array}$

(a) The impact of $\mathrm{L}$ on $\mathrm{p}_{1}$

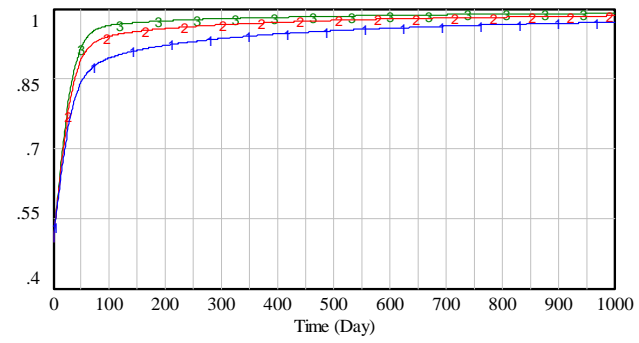

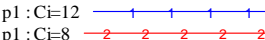

(b) The impact of $\mathrm{Ci}$ on $\mathrm{p}_{1}$

Fig. 9. The impact of parameter changes on the evolutionary results of tourism enterprises.

(2) The impact of parameter changes on the strategy of residents

When tourism enterprises implement ecotourism and residents participate in environmental management, environmental and cultural quality improvement will bring benefits Ay. As shown in Fig.10(a). This shows that the greater Ay, the greater the possibility of residents choose to participate in ecotourism and finally reach the stability.

The reward R of local government for the participation of residents in ecotourism affects residents' willingness. As shown in Fig.10(b), the value of reward R ranges from $2 \rightarrow 4 \rightarrow 6$, and the steepness of the responding curve is getting bigger and bigger. That is, the willingness of residents to participate in ecotourism increases with the increase of reward R.

There is opportunity cost Oc for residents to participate in environmental management. As shown in Fig.10(c), let $\mathrm{Oc}=3, \mathrm{Oc}=6$, and $\mathrm{Oc}=9$. In the corresponding three curves, it can be seen that the curve 3 corresponding to $\mathrm{Oc}=9$ has the steepest degree, and the speed of approaching 0 is also the greatest.

That is, the greater the opportunity cost, the less likely the residents will choose to participate in ecotourism. 


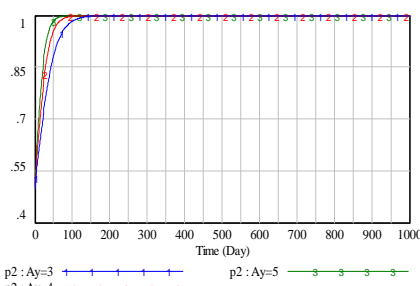

$\mathrm{p} 2: \mathrm{A}=3 \mathrm{~B}$
$\mathrm{p} 2 \mathrm{~A}=\mathrm{A}=4$

(a) The impact of Ay on $p_{2}$

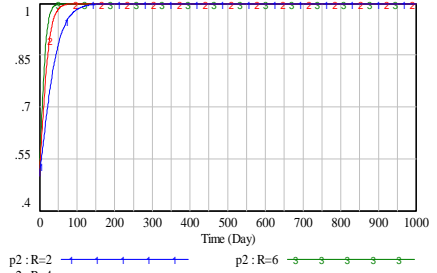

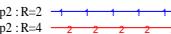

(b) The impact of $\mathrm{R}$ on $\mathrm{p}_{2}$

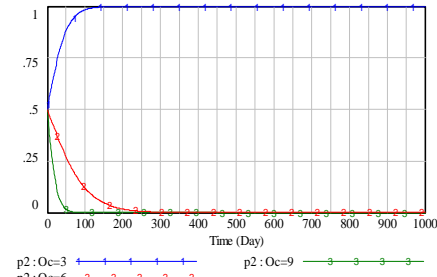

(c) The impact of Oc on $\mathrm{p}_{2}$

Fig. 10. The impact of parameter changes on the evolutionary results of residents.

(3) The impact of parameter changes on the strategy of local governments

The local government afford the reward $\mathrm{R}$ for residents participating in ecotourism. As shown in Fig.11(a), when the value of $\mathrm{R}$ increases from 2 to 6 , the curve changes from 1 to 3 , that is, the government's willingness to choose not to supervise increases. The greater the reward is given by the government, the lower the probability of government supervision.

The losses Li incurred when local governments do not implement supervision and are tipped off by the public, which is similar to the reputation losses of local governments not implementing supervision Lr. As shown in Fig.11(b), let $\mathrm{Li}=6, \mathrm{Li}=8$, and $\mathrm{Li}=12$. Among the three curves corresponding to the three values of $\mathrm{Li}$, the fluctuation amplitude of curve 3 is the most obvious, and there is a tendency to approach 1 quickly. That is to say, the greater of $\mathrm{Li}$, the greater the probability that the local government will choose a supervision strategy.

Usually, the local government's supervision cost $\mathrm{C}$ will have an impact on the government's strategic choice. As shown in Fig.11(c), let $\mathrm{C}=1, \mathrm{C}=3$, and $\mathrm{C}=4$, it can be seen that the increase in cost will lead the government to tend to choose an unsupervised strategy.

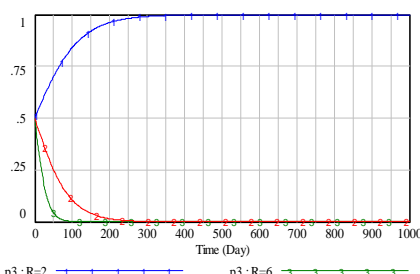

$\mathrm{p} 3: \mathrm{R}=2$
$\mathrm{p} 3: \mathrm{R}=4$

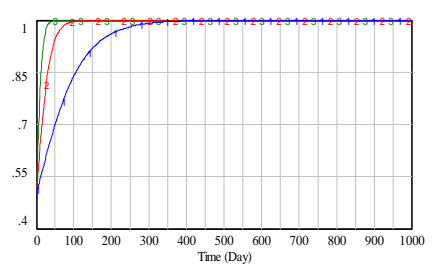

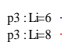

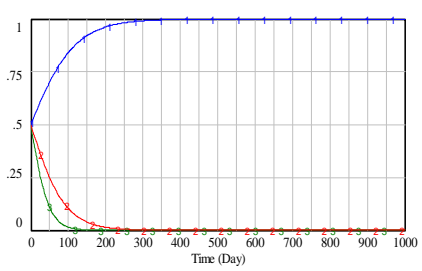

$\mathrm{p} 3: \mathrm{C}=1$
$\mathrm{p}: \mathrm{C}: \mathrm{C}=3$ $\mathrm{p} 3: \mathrm{C}=4$

$\mathrm{p} 3: \mathrm{C}=4$ 

(a) The impact of $\mathrm{R}$ on $\mathrm{p}_{3}$
(b) The impact of Li on $\mathrm{p}_{3}$
(c) The impact of $\mathrm{C}$ on $\mathrm{p}_{3}$

Fig. 11. The impact of parameter changes on the evolutionary results of local government.

(4) The impact of incentive and penalty changes on evolutionary results

When the incentive and the penalty in the optimization model are dynamically adjusted, the strategies of the three stakeholders in ecotourism will change accordingly. Fig.12(a) and 12(b) respectively show the impact of incentive and penalty changes on the choice of tourism enterprises. As can be seen from Fig.12(a), when both the incentive and the penalty increase simultaneously, tourism enterprises are more inclined to choose to implement ecotourism. As can be seen from Fig.12(b), when the penalty coefficients $a_{11}$ and $a_{22}$ are larger than the incentive coefficients $b_{11}$ and $b_{22}$, the curve 2 tends to be stable for a shorter period, that is, the severe punishment measures enable the tourism enterprises to actively choose to implement ecotourism.
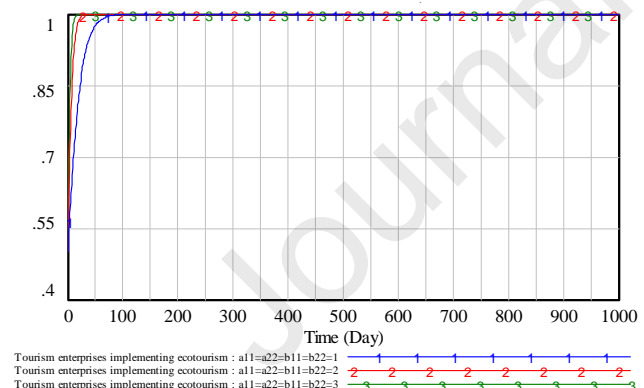

(a) the incentive and penalty increase simultaneously.
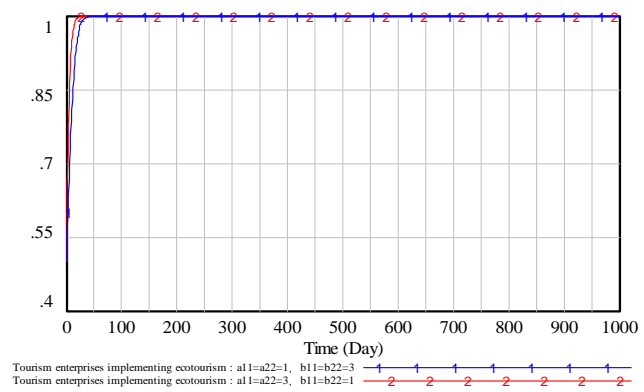

(b) the incentive and penalty increase respectively.

Fig. 12. The impact of incentive and penalty changes on evolutionary results.

\section{Results and discussion}

From the above simulation analysis, we can get the following results:

(1) When the multi-player evolutionary game of development and construction of ecotourism in ecologically fragile areas was simulated without implementing effective stability control measures, the 
strategic choices of local governments, tourism enterprises and residents fluctuated repeatedly, and there was no stable strategy in the evolutionary process.

Man and Ne (2019) also mentioned in their work that the stakeholders must collaborate to address environmental issues. At this time, as long as anyone of the three parties in the game changes slightly without effective stability control measures, the fluctuation of the equilibrium strategy point will appear, and the relative equilibrium state will be broken (Tseng et al., 2019). The previous works verified the correctness of our conclusions and research findings.

(2) To further optimize the control, dynamic penalty-incentive measures were taken to stabilize the fluctuation of the multi-player game in the development and construction of ecotourism in ecologically fragile areas, and an ideal strategy was obtained.

Sun et al. (2019) also mentioned in their work that it is essential for local government, citizens and tourists to take effective measures for the economic construction and development of forest eco-tourism attractions. To reach a steady-state, Liu et al., (2015) and Liu and Li, (2015) adopted a dynamic penalty-incentive measure to achieve the stability of the evolution in their researches. However, there are some significant problems in the development and construction of ecotourism in ecologically fragile areas, especially in the strategic game among the various stakeholders to maximize their respective interests (Osman et al., 2018; Tseng et al., 2019). Existing studies are surprisingly unconcerned about interest conflicts of stakeholders in the ecotourism in ecologically fragile areas. The previous works verified the correctness of our conclusions and research findings.

For the ecotourism, our research proved that the proposed dynamic penalty-incentive measures were very effective in controlling the fluctuation of the three parties of the game, and the strategies of the three parties of the game and an ideal evolutionarily stable strategy were obtained under such 
control conditions. This provided a theoretical and practical contribution for achieving a win-win situation among the three parties in ecotourism in ecologically fragile areas.

(3) In the process of setting the initial value of two stakeholders as the Nash equilibrium value and observing the third-party strategy, the greater the initial value of the probability of tourism enterprises implementing ecotourism, the easier it was to reach the final stable state.

Font et al., (2016) found that small firms are more involved in taking responsibility for being sustainable than previously expected, including eco-savings related operational practices. As Sharma and Sarmah (2019) mentioned in their work, various strategies tourism and hospitality firms can use to prioritize factors and co-creating a replicable model of service innovation. Margaryan and Stensland (2017) suggest that companies with strong beliefs in the positive context and sustainability-oriented business goals are more likely to invest in an eco-certification scheme. The previous works verified the correctness of our conclusions and research findings.

(4) The impact of each factor on evolutionary results of stakeholders can be analysed. The losses incurred to tourism enterprises not implementing ecotourism and the cost tourism enterprises implementing ecotourism can influence the choice of tourism enterprises. The benefits from environmental and cultural quality improvement, rewards from local governments to residents participating in ecotourism and opportunity cost of residents participating in environmental protection can also make the effects on the strategy of residents. The reputation losses of local governments not implementing supervision and rewards from local governments to residents participating in ecotourism, losses incurred when local governments do not implement supervision and are tipped off by the public and supervision cost of local governments can influence the strategy of local government.

Previous literature analysed the Nash Equilibrium of government, tourism enterprises and tourists 
during the development of eco-tourism by balancing their interests (Min, 2015), and the conclusions obtained from our research are verified by previous research (Fei, 2015; Huang et al., 2015). However, previous studies were surprisingly unconcerned about the stability of evolution about interest conflicts of stakeholders and sustainable development in the ecotourism in ecologically fragile areas. Of course, we suggest that dynamic incentives and punishment strategies can effectively promote ecotourism. This sustainable development pattern of eco-tourism can depict the relations among the stakeholders and the effects of the choices on the satisfaction. This provided a theoretical and practical contribution for achieving a win-win situation among the three parties in ecotourism in ecologically fragile areas.

\section{Conclusions and policy implications}

Green governance is a coordination process of multiple stakeholders in which the optimal intensity of environmental regulations to meet the interests of various stakeholders (Jordan et al., 2005). Aiming at the characteristics of multi-player complex dynamic game and multi-party participation in the development and construction of ecotourism in ecologically fragile areas, a multi-player evolutionary game model of development and construction of ecotourism in ecologically fragile areas based on SD is established by combining the idea of a dynamic evolutionary game with the means of computer simulation based on system dynamics. By solving and simulating the model, this paper proposes control measures capable of effectively controlling the fluctuation of the game process, and optimizes the supervision control measures. The optimized control measures can effectively suppress the fluctuation of the strategies of the three parties of the game, and finally, an ideal evolutionarily stable strategy is obtained. Besides, changes in factors in the evolution can affect the strategic choices of stakeholders, which in turn will affect the sustainable development of ecotourism in ecologically fragile areas. The appropriate dynamic incentives and punishment strategies to promote the 
development of ecotourism contributed to the environmental and sustainability research and practice.

In the multi-player game of development and construction of ecotourism in ecologically fragile areas, the participation of tourism enterprises, residents and local governments in the game is analysed. Here, the conclusions drawn from this study are listed below.

(1) In the multi-player game of development and construction of ecotourism in ecologically fragile areas, this paper combined the game theory with the dynamic analysis and utilized system dynamics to simulate, which is more suitable for the long-term dynamic game among all parties of the game.

Osman et al. (2018) also suggested that any stakeholder involvement has tended towards a consultative rather than a collaborative approach. Developing any mutual understanding, by listening to stakeholder views and interests, to build a consensus between the stakeholder groups was not achieved. Wondirad et al., (2020) found that the lack of effective stakeholder collaboration features prominently hindered the success of ecotourism, revealed poor interactions and collaborations amongst ecotourism stakeholders. Nevertheless, Chang et al.,(2017) and Liu et al., (2015) applied system dynamics to simulate the evolutionary game process of the stakeholders' participation, then an effective method can be obtained and a move towards greater collaboration among the stakeholder groups could be realized. We also aimed at the characteristics of multi-player complex dynamic game and multi-party participation in the development and construction of ecotourism in ecologically fragile areas. A multi-player evolutionary game model of development and construction of ecotourism in ecologically fragile areas based on system dynamics was established and dynamic incentives and punishment strategies were proposed by combining the idea of a dynamic evolutionary game with the means of computer simulation. The optimized control measures can effectively suppress the fluctuation and then an ideal evolutionarily stable strategy was obtained. This provided a theoretical and practical 
contribution in ecotourism in ecologically fragile areas for combining the game theory with the dynamic analysis to achieve a win-win situation.

(2) The strategic choices of tourism enterprises, residents and local governments fluctuate repeatedly. These fluctuations make it difficult for local governments to effectively design and implement inspection strategies, which lead to the frequent occurrence of ecological environment problems in the development and construction of ecotourism in ecologically fragile areas, will inevitably restrict the process of development and construction of ecotourism in ecologically fragile areas and hinder the protection of the ecological environment and economic development in ecologically fragile areas.

Lee and Son (2016) revealed the issue of facility development in government-led ecotourism and the absence of an actual goal and consequently chaotic management in resident-led ecotourism. Furthermore, both the systems face the issue of consensus concerning the management of regulation, space, safety, land price, and industrial structure. Tseng et al., (2019) also found that the fluctuation of the equilibrium strategy point will appear as long as anyone of the stakeholders in the game changes slightly without effective stability control measures, and the relative equilibrium state would be broken. We analysed the participation and evolutionary mechanism and simulates the evolutionary process of the stakeholders in ecotourism, and found that the fluctuation of the equilibrium strategy point of the stakeholders in the game changes without effective stability control measures, which laid a solid foundation for the next step to propose a specific solution. The previous works verified the correctness of our conclusions and research findings.

(3) Besides, this paper proposed the dynamic penalty-incentive control method to optimize the control fluctuation and then carries out the numerical simulation. 
Su et al. (2014) found that current relationships between people, resources, and tourism have yet to provide mutual benefits necessary for successful ecotourism. Government decisions and actions can affect ecological security and tourism industry development (Tang et al., 2018). As several prior studies illustrated, the multi-stakeholder management style and the lack of mechanisms for participation constitute structural difficulties for ecotourism management and operation. Therefore, it is recommended that management programs and government policies should be established to provide a platform for community participation in ecotourism. Ocampo et al. (2018) also illustrated the relationship among different stakeholders, analysis contradictions and conflicts of stakeholders separately from perspectives of the ownership relationship, resources management, interests achieve in the tourism development process, to explain the causes of the conflict and propose a coordinated mechanism to alleviate conflicts.

Liu et al., (2015) and Liu and Li, (2015) applied a dynamic penalty-incentive measure to achieve the stability of the evolution in their researches. For the ecotourism in ecologically fragile areas, the various stakeholders maximized their respective interests (Osman et al., 2018; Tseng et al., 2019). Existing studies were surprisingly unconcerned about interest conflicts of stakeholders. In our research, the dynamic penalty-incentive control method can not only effectively suppress the fluctuation, but also provide an ideal evolutionarily stable strategy. The tourism enterprises will almost choose to implement ecotourism as their optimal strategies. The previous works verified the correctness of our conclusions and research findings which provided a theoretical and practical contribution in ecotourism in ecologically fragile areas for achieving a win-win situation among the three parties.

(4) From the perspective of tourism enterprises, it is found that the greater the loss suffered by not implementing ecotourism, the greater the tendency of tourism enterprises to choose to implement 
ecotourism.

The results suggested that companies with strong beliefs in the positive context and sustainability-oriented business goals are more likely to invest in an eco-certification scheme (Margaryan and Stensland, 2017). Under this circumstance, the tourism enterprise should estimate the loss and choose a strategy that is more favourable to itself. It is also found that the higher the cost of ecotourism for tourism enterprises, the lower their willingness to implement ecotourism. Carvache-Franco et al. (2019) mentioned in their work, the public institutions and private companies should improve their tourist offerings, benefit the destination and develop a more effective marketing strategy. Tourism enterprises should consider their profitability and conduct strict cost control to obtain higher profits in ecotourism. The previous works verified the correctness of our conclusions and research findings which provided the foundation of theoretical and practices for tourism enterprises to achieve collaborative development in ecotourism in ecologically fragile areas.

(5) From the perspective of residents, it is found that the environmental and cultural quality improvement can stimulate residents to choose to participate in ecotourism, although this kind of income is hard to weight now, it is the ultimate goal of ecotourism.

Similar results were presented by Kim (2017), that residents were in favour of the introduction of eco-tourism and associated administration agency and local government should cooperate when the policies are established. The increase of government reward for residents can enhance the willingness to participate in ecotourism to some extent. However, as time goes by, the incentive level of reward will gradually weaken. The greater the opportunity cost of residents participating in environmental management, the lower the probability that residents will choose to participate. Residents' participation in ecotourism comes from subjective will, and they consider the maximization of their interests. 
Wondirad et al., (2020) found that in poorly resourced and remote destinations, failure to empower and participate communities undermines ecotourism and jeopardizes the long-term survival of ecosystems and communities themselves. Chen and Law (2012) also mentioned in their work that residents value the surroundings more than visitors clue to their higher reliance on them and their interactions with them, the sustainable development of ecotourism can maintain the values generated from the surroundings. Therefore, while providing rewards for residents to participate in ecotourism, the government should also focus on long-term effects and encourage residents to participate in ecotourism by reducing opportunity costs and through vigorous publicity and education. The previous works verified the correctness of our conclusions and research findings which provided the foundation of theoretical and practices for residents to actively participate in ecotourism.

(6) The greater the loss of reputation that the local government does not supervise, the more the local government tends to implement supervision. Since reputation losses are extremely difficult to recover, the government should try to avoid it. The greater the government's incentives for residents to participate in ecotourism, the greater willingness of the government to choose not to supervise. Although rewards increase the enthusiasm of residents to participate in ecotourism, the incentives brought by such rewards will diminish over time. Then, the government should develop diversified motivating measures. In fact, the increase in supervision costs of the local government will lead the government to choose incentive measures instead of unsupervised strategy. Besides, compared with the implementation of stronger incentives, the government should set strict penalties, which will encourage tourism enterprises to actively choose to implement ecotourism.

That is to say, the government needs to conduct environmental supervision while reducing the cost of supervision. When the government punishment quota is low and the supervision cost is too high, the 
government needs to encourage enterprises and people to actively participate in ecotourism through incentive measures, thereby reducing the cost of government supervision. Similar results were presented by Zheng et al. (2017), that environmental education and professional performance are eventually proposed to assist domestic eco-tourism in stable and continuous growth. Su et al. (2014) found that the relationships between people, resources, and tourism have yet to provide mutual benefits necessary for successful ecotourism. The multi-stakeholder management style and the ambiguity of land ownership within the nature reserve constitute structural difficulties for ecotourism management and operation. Therefore, it is recommended that management programs and government policies should be established to provide a platform for community participation in ecotourism. The most important thing is, according to the dynamic penalty-incentive control method proposed in the paper, that the government should dynamically balance the strength of the incentives and penalties, to better mobilize the enthusiasm of tourism enterprises to implement ecotourism. The previous works verified the correctness of our conclusions and research findings which provided a theoretical and practical contribution for achieving a win-win situation among the three parties in ecotourism in ecologically fragile areas.

However, there are some inevitable limitations in the study of this paper. For example, the stakeholders in the model setting are relatively simple. In fact, many other stakeholders will have an impact on the system for supervising the implementation of ecotourism by the tourism enterprises, such as relevant stakeholders (environmental protection, wildlife, social groups, etc.) or tourists (Huang, 2017), who will affect the system studied in this paper more or less. In the future studies, it will be necessary to develop more complex and comprehensive modes to study the system for local governments to supervise the implementation of ecotourism by tourism enterprises (D'Amato et al., 
2017).

\section{Acknowledgements}

This research is supported by the National Social Science Fund of China (18BJY118), the 2020 Sichuan International Science and Technology Innovation Cooperation Project (20GJHZ0039), the Social Science Planning Project of Sichuan Province (SC19B111), Sichuan National Mountain Economic Development Research Center Project (SDJJ1805). The authors would like to express their sincere thanks to the anonymous reviewers for their constructive comments and suggestions in improving this paper.

\section{References}

Aliani, H., Kafaky, S.B., Monavari, S.M., Dourani, K., 2018. Modeling and prediction of future ecotourism conditions applying system dynamics. Environ. Monit. Assess. 190. https://doi.org/10.1007/s10661-018-7078-4

Carvache-Franco, M., Segarra-Ona, M., Carrascosa-Lopez, C., 2019. Segmentation and motivations in ecotourism: The case of a coastal national park. Ocean Coast. Manag. 178.

Chang, J.W., Zhao, L.W., Du, J.G., 2017. Evolutionary game analysis and stability control scenarios of corporate environmental behavior inspection based on system dynamics. Syst. Eng. 35, 79-87.

Chen, W.J., Law, S.C., 2012. What is the value of ecotourism? An evaluation of forested trails for community residents and visitors. Tour. Econ. 18, 871-885.

Chen, X.H., 2017. A new model of tourism enterprise management under the concept of ecotourism management. Technol. Ind. Across Straits 7, 87-88.

Cheng, M., Zhu, Q.C., Dong, D.M., 2011. Game study on construction safety supervision based on 
$\begin{array}{llllll}\text { system dynamics. } & \text { China } & \text { Saf. } & \text { Sci. } & \text { J. } & \text { 21, }\end{array}$ https://doi.org/10.16265/j.cnki.issn1003-3033.2011.12.007

Choi, M.A., 2020. Multiple environmental subjects: Governmentalities of ecotourism development in Jeungdo, South Korea. Geoforum 110, 77-86. https://doi.org/10.1016/j.geoforum.2020.01.011

D’Amato, D., Droste, N., Allen, B., Kettunen, M., Lahtinen, K., Korhonen, J., Leskinen, P., Matthies, B.., Toppinen, A., 2017. Green, circular, bioeconomy: A comparative analysis of sustainability avenues. J. Clean. Prod. 168, 716-734.

Deng, X.Z., Wang, Z., Zhao, C.H., 2016. Economic evolution in china ecologically fragile regions. J. Econ. Surv. 30, 552-576. https://doi.org/10.1017/CBO9781107415324.004

Dey, J., Sakhre, S., Gupta, V., Vijay, R., Pathak, S., Biniwale, R., Kumar, R., 2018. Geospatial assessment of tourism impact on land environment of Dehradun, Uttarakhand, India. Environ. Monit. Assess. 190, 181.

Diamantis, D., 2018. Stakeholder ecotourism management: Exchanges, coordination's and adaptations. J. Ecotourism 17, 203-205. https://doi.org/10.1080/14724049.2018.1502122

Ding, Q., Shi, X., Zhuang, D.F., Wang, Y., 2018. Temporal and spatial distributions of ecological vulnerability under the influence of natural and anthropogenic factors in an ecoprovince under construction in China. Sustain. 10. https://doi.org/10.3390/su10093087

Ding, Z.F., Cao, B., 2019. Exploring the factors in visitors' behavioral intentions mediation effects on perceived environmental involvement and ecotourism support. Appl. Ecol. Environ. Res. 17, 1083-1092. https://doi.org/10.15666/aeer/1701_10831092

Fang, H.L., Yu, B., Zhang, D.F., Ai, Y., 2012. Causes and countermeasures of interest contradiction in stakeholders of ecotourism in forestry nature reserves. J. Northwest For. Univ. 27, 252-257. 
https://doi.org/10.1017/CBO9781107415324.004

Fang, Y.J., Wei, W., Liu, F., Mei, S.W., Chen, L.J., Li, J.J., 2019. Improving solar power usage with electric vehicles: Analyzing a public-private partnership cooperation scheme based on evolutionary game theory. J. Clean. Prod. 233, 1284-1297. https://doi.org/10.1016/j.jclepro.2019.06.001

Fei, W., 2015. Investigation on game behaviors of stakeholders in ecotourism exploitation of famous historical and cultural towns and villages. Ecol. Econ. 31, 142-146.

Feng, X.D., Xu, C., 2012. Core stakeholders and governance mechanism in Zhalong National Nature Reserve. J. Beijing For. Univ. 11, 89-93.

Font, X., Garay, L., Jones, S., 2016. Sustainability motivations and practices in small tourism enterprises in European protected areas. J. Clean. Prod. 137, 1439-1448.

Friedman, D., 1991. Evolutionary games in economics. Econometrica 59, 637. https://doi.org/10.2307/2938222

Guo, L.L., Qu, Y., Wu, C.Y., Wang, X.L., 2018. Identifying a pathway towards green growth of Chinese industrial regions based on a system dynamics approach. Resour. Conserv. Recycl. 128, $143-154$.

Hagenlocher, M., Renaud, F.G., Haas, S., Sebesvari, Z., 2018. Vulnerability and risk of deltaic social-ecological systems exposed to multiple hazards. Sci. Total Environ. 631-632, 71-80. https://doi.org/10.1016/j.scitotenv.2018.03.013

He, Y., Huang, P., Xu, H., 2018. Simulation of a dynamical ecotourism system with low carbon activity: A case from western China. J. Environ. Manage. 206, 1243-1252. https://doi.org/10.1016/j.jenvman.2017.09.008 
Huang, X.X., Hu, Z.P., Fu, C., Yu, D.J., 2015. Evolutionary game analysis on the main stakeholders in ecotourism. Ecol. Econ. 31, 142-146.

Huang, X.Y., Li, B., Zhou, J.Y., Gao, M., Zhou, Y.Y., 2009. Evaluation of ecological vulnerability of Jiangsu coastal areas. Environ. Sci. Technol. 22, 53-56.

Huang, Z.H., 2017. Ecotourism stakeholder analysis. Tour. Overv. 69-70.

Jiang, K., You, D.M., Merrill, R., Li, Z.D., 2019. Implementation of a multiagent environmental regulation strategy under Chinese fiscal decentralization: An evolutionary game theoretical approach. J. Clean. Prod. 214, 902-915. https://doi.org/10.1016/j.jclepro.2018.12.252

Jordan, A., Wurzel, R.., Zito, A., 2005. The rise of 'new'policy instruments in comparative perspective: Has governance eclipsed government? Polit. Stud 53, 477-496.

Kan, A.K., Li, G.Q., Yang, X., Zeng, Y.L., Tesren, L.B., He, J., 2018. Ecological vulnerability analysis of Tibetan towns with tourism-based economy: A case study of the Bayi District. J. Mt. Sci. 15, 1101-1114. https://doi.org/10.1007/s11629-017-4789-x

Kang, H., Tao, W.D., Chang, Y., Zhang, Y., Xuxiang, L., Chen, P., 2018. A feasible method for the division of ecological vulnerability and its driving forces in Southern Shaanxi. J. Clean. Prod. 205, 619-628. https://doi.org/10.1016/j.jclepro.2018.09.109

Kim, J.H., 2017. A research on recognition and needs of mountain village residents about the introduction of mountain ecotourism. J. Korean For. Soc. 106, 353-361.

Kuang, X.J., 2010. Location analysis on stakeholders and theirs role orientation in development of ecological tourism. J. Cent. South Univ. For. Technol. 30, 81-84.

Lee, J., 2019. Conflict mapping toward ecotourism facility foundation using spatial Q methodology. 
Lee, J.H., Choi, H.O., 2017. Stakeholders' views on reducing financial support in governmentled $\begin{array}{llllll}\text { ecotourism } & \text { areas. } & \text { Ocean } & \text { Coast. } & \text { Manag. } & 144,\end{array}$ https://doi.org/10.1016/j.ocecoaman.2017.03.033

Lee, J.H., Kim, S.H., Kwon, H.S., 2017. Mapping interests by stakeholders' subjectivities toward ecotourism resources: The case of Seocheon-Gun, Korea. Sustain. 9. https://doi.org/10.3390/su9010093

Lee, J.H., Son, Y.H., 2016. Stakeholder subjectives toward ecotourism development using Q methodology: The case of Maha ecotourism site in Pyeongchang, Korea. Asia Pacific J. Tour. Res. 21, 931-951. https://doi.org/10.1080/10941665.2015.1084347

Lee, T.H., Jan, F.H., 2018. Ecotourism behavior of nature-based tourists: An integrative framework. J. Travel Res. 57, 792-810. https://doi.org/10.1177/0047287517717350

Lee, T.H., Jan, F.H., 2015. The effects of recreation experience, environmental attitude, and biospheric value on the environmentally responsible behavior of nature-based tourists. Environ. Manage. 56, 193-208. https://doi.org/10.1007/s00267-015-0488-y

Li, C.D., Zhang, F.S., Cao, C.J., Liu, Y., Qu, T., 2019. Organizational coordination in sustainable humanitarian supply chain: An evolutionary game approach. J. Clean. Prod. 219, 291-303. https://doi.org/10.1016/j.jclepro.2019.01.233

Li, X.Q., 2011. Study of interests demand of the main stakeholders: Taking daming mount national nature reserve in Guangxi as a case. Ecol. Econ. 10, 141-147.

Li, Y., Sun, Q., Bandara, Y.M.W.Y., Sharma, K., Hicks, J., Basu, P.K., 2018. The economic impact of ecotourism on regional China: Further evidence from Yunnan and Sichuan provinces. Glob. Bus. Rev. 19, 533-542. 
Li, Y.Y., Filimonau, V., Wang, L., Cheng, S.K., 2020. Tourist food consumption and its arable land requirements in a popular tourist destination. Resour. Conserv. Recycl. 153. https://doi.org/10.1016/j.resconrec.2019.104587

Liu, J.Y., 2006. Viewing the structure relationship among ecotourism stakeholders from the perspective of systematology. Tour. Trib. 21, 17-21.

Liu, Q.L., Li, X.C., 2015. Effective stability control research of evolutionary game in China's coal mine safety supervision. J. Beijing Inst. Technol. Sci. Ed. 17, 49-56. https://doi.org/10.1377/hlthaff.2013.0625

Liu, Q.L., Li, X.C., Maureen, H., 2015. Evolutionary game analysis and stability control scenarios of coal mine safety inspection system in China based on system dynamics. Saf. Sci. 80, 22.

Lonn, P., Mizoue, N., Ota, T., Kajisa, T., Yoshida, S., 2018. Evaluating the contribution of community-based ecotourism (CBET) to household income and livelihood changes: A case study of the Chambok CBET program in Cambodia. Ecol. Econ. 151, 62-69. https://doi.org/10.1016/j.ecolecon.2018.04.036

Lu, X.T., Lu, Y.L., Chen, D.L., Su, C., Song, S., Wang, T.Y., Tian, H.Q., Liang, R.Y., Zhang, M., Khan, K., 2019. Climate change induced eutrophication of cold-water lake in an ecologically fragile nature reserve. J. Environ. Sci. 75, 359-369. https://doi.org/10.1016/j.jes.2018.05.018

Ma, B., Cai, Z., Zheng, J., Wen, Y.L., 2019. Conservation, ecotourism, poverty, and income inequality - a case study of nature reserves in Qinling, China. World Dev. 115, 236-244.

Man, Z., Ne, Y.E., 2019. Orang Asli participation in ecotourism activities at Tasik Chini, Pahang, Malaysia. Geogr. J. Soc. Sp. 15, 50-63.

Margaryan, L., Stensland, S., 2017. Sustainable by nature? The case of (non)adoption of 
eco-certification among the nature-based tourism companies in Scandinavia. J. Clean. Prod. 162, $559-567$.

Masih, M., Jozi, S.A., Lahijanian, A.A.M., Danehkar, A., Vafaeinejad, A., 2018. Capability assessment and tourism development model verification of Haraz watershed using analytical hierarchy process (AHP). Environ. Monit. Assess. 190, 1. https://doi.org/10.1007/s10661-018-6823-z

Massingham, E., Fuller, R.A., Dean, A.J., 2019. Pathways between contrasting ecotourism experiences and conservation engagement. Biodivers. Conserv. 28, 827-845. https://doi.org/10.1007/s10531-018-01694-4

Min, W., 2015. Sustainable development pattern of ecotourism based on stakeholders. Anthropologist $22,650-661$.

Motlagh, E.Y., Hajjarian, M., Zadeh, O.H., Alijanpour, A., 2020. The difference of expert opinion on the forest-based ecotourism development in developed countries and Iran. Land use policy 94. https://doi.org/10.1016/j.landusepol.2020.104549

Mtapuri, O., Giampiccoli, A., 2019. Tourism, community-based tourism and ecotourism: A definitional $\begin{array}{lllll}\text { problematic. } & \text { South }\end{array}$ https://doi.org/10.1080/03736245.2018.1522598

Ocampo, L., Angela Ebisa, J., Ombe, J., Geen Escoto, M., 2018. Sustainable ecotourism indicators with fuzzy Delphi method a philippine perspective. Ecol. Indic. 93, 874-888. https://doi.org/10.1016/j.ecolind.2018.05.060

Osman, T., Shaw, D., Kenawy, E., 2018. Examining the extent to which stakeholder collaboration during ecotourism planning processes could be applied within an Egyptian context. Land use policy 78, 126-137. https://doi.org/10.1016/j.landusepol.2018.06.043 
Peng, F.W., Zhong, L.S., Yuan, H., 2017. Study on ecotourism development planning of China. China Tourism Press,Beijing,China.

Peng, J., Xu, Y.Q., Cai, Y.L., Xiao, H.L., 2011. The role of policies in land use/cover change since the 1970s in ecologically fragile karst areas of southwest China: A case study on the Maotiaohe watershed. Environ. Sci. Policy 14, 408-418. https://doi.org/10.1016/j.envsci.2011.03.009

Phelan, A. (Anya), Ruhanen, L., Mair, J., 2020. Ecosystem services approach for community-based ecotourism: Towards an equitable and sustainable blue economy. J. Sustain. Tour. 28, 16651685. https://doi.org/10.1080/09669582.2020.1747475

Qi, X.H., Ye, S. li., Cheng, Y., Lin, R.P., 2013. The game analysis between poverty and environment in ecologically fragile zones. Acta Ecol. Sin. 33, 6411-6417.

Ran, Q., Su, Z.X., Ran, J., 2009. Causes and countermeasures of interest contradiction in stakeholders of ecotourism in forestry nature reserves. Rural Econ. Sci. 20, 71-73. https://doi.org/10.1017/CBO9781107415324.004

Sharma, N., Sarmah, B., 2019. Consumer engagement in village ecotourism: A case of the cleanest village in Asia - Mawlynnong. J. Glob. Sch. Mark. Sci. 29, 248-265.

Sheng, J.C., Zhou, W.H., Zhu, B.Z., 2020. The coordination of stakeholder interests in environmental regulation: Lessons from China's environmental regulation policies from the perspective of the evolutionary game theory. J. Clean. Prod. 249, 119385. https://doi.org/10.1016/j.jclepro.2019.119385

Shi, F.F., Weaver, D., Zhao, Y.Z., Huang, M.F., Tang, C.Z., Liu, Y., 2019. Toward an ecological civilization: Mass comprehensive ecotourism indications among domestic visitors to a Chinese wetland protected area. Tour. Manag. 70, 59-68. https://doi.org/10.1016/j.tourman.2018.07.011 
Snyman, S., 2017. The role of private sector ecotourism in local socio-economic development in southern Africa. J. Ecotourism 16, 247-268.

Su, M.M., Wall, G., Ma, Z., 2014. Assessing ecotourism from a multi-stakeholder perspective: Xingkai lake national nature reserve, China. Environ. Manage. 54, 1190-1207. https://doi.org/10.1007/s00267-014-0360-5

Sun, Q., Nie, X.P., Tan, Z.Y., Su, W., 2019. Economic benefit evaluation of forest ecotourism attractions based on factor analysis. Ital. J. Pure Appl. Math. 41, 104-115.

Sun, Z.Y., Zhang, W.W., 2019. Do government regulations prevent greenwashing? An evolutionary game analysis of heterogeneous. J. Clean. Prod. 231, 1489-1502.

Tan, S.H., Li, T.Y., Huntsinger, L., 2018. Analyzing herder adaptive capacity to climate change:A case study from an ecologically fragile area in inner Mongolia, people's republic of China. Hum. Ecol. 46, 399-409.

Tang, C.C., Wu, X.F., Zheng, Q.Q., Lyu, N., 2018. Ecological security evaluations of the tourism industry in ecological conservation development areas: A case study of Beijing's ECDA. J. Clean. Prod. 197, 999-1010.

Tseng, M.L., Lin, C.Y., Lin, C.W.R., Wu, K.J., Sriphon, T., 2019. Ecotourism development in Thailand: Community participation leads to the value of attractions using linguistic preferences. J. Clean. Prod. 231, 1319-1329.

Vidović, A.B., 2018. Ecotourism management for development countries. Tehnika 73, 293-299.

Wang, H.W., Cai, L.R., Zeng, W., 2011. Research on the evolutionary game of environmental pollution in system dynamics model. J. Exp. Theor. Artif. Intell. 23, 39-50. https://doi.org/10.1080/0952813X.2010.506300 
Wang, J., Horne, A., Nathan, R., Peel, M., Neave, I., 2018. Vulnerability of ecological condition to the sequencing of wet and dry spells prior to and during the Murray-Darling basin $\begin{array}{lllllll}\text { millenniumdrought. J. Water } & \text { Resour. Plan. Manag. }\end{array}$ https://doi.org/10.1061/(ASCE)WR.1943-5452.0000963

Withanachchi, S.S., Kunchulia, I., Ghambashidze, G., Al Sidawi, R., Urushadze, T., Ploeger, A., 2018. Farmers' perception of water quality and risks in the Mashavera River Basin, Georgia: Analyzing the vulnerability of the social-ecological system through community perceptions. Sustain. 10, 126. https://doi.org/10.3390/su10093062

Wondirad, A., Tolkach, D., King, B., 2020. Stakeholder collaboration as a major factor for sustainable ecotourism development in developing countries. Tour. Manag. 78. https://doi.org/10.1016/j.tourman.2019.104024

Wu, C.Y., Guo, L.L., Yu, J.T., 2013. Dynamic simulation of regional ecological security of tourism. Syst. Eng. 31, 94-99.

Xie, Z.L., Li, X.Z., Jiang, D.G., Lin, S.W., Yang, B., Chen, S.L., 2019. Threshold of island anthropogenic disturbance based on ecological vulnerability Assessment-a case study of Zhujiajian Island. Ocean Coast. Manag. 167, 127-136. https://doi.org/10.1016/j.ocecoaman.2018.10.014

Yan, Y., Zhao, C.L., Quan, Y., Lu, H.T., Rong, Y., Wu, G., 2017. Interrelations of ecosystem services and rural population wellbeing in an ecologically fragile area in North China. Sustain. 9, 709. https://doi.org/10.3390/su9050709

Yang, Z., Li, W.P., Pei, Y.B., Qiao, W., Wu, Y. 1., 2018. Classification of the type of eco-geological environment of a coal mine district: A case study of an ecologically fragile region in western 
China. J. Clean. Prod. 174, 1513-1526. https://doi.org/10.1016/j.jclepro.2017.11.049

Ye, W., Zhang, Y.Y., Li, H.B., 2018. The report on ecotourism development in China. Science Press,Beijing,China.

Yu, S., Wang, H.L., 2010. Studies on the win-win development model of ecological protection and economic development in the ecologically fragile areas in northwest China. Environ. Ecol. Three Gorges 32, 11-14.

Zhang, J.K., 2017. Evaluating regional low-carbon tourism strategies using the fuzzy Delphi-analytic network process approach. J. Clean. Prod. 141, 409-419.

Zheng, Q.J., Xu, A.X., Kong, D.Y., 2017. Environmental education, knowledge management and professional performance in ecotourism: The impact relatedness. Eurasia J. Math. Sci. Technol. Educ. 13, 4679-4687. 


\section{Highlights}

- Conflicts of interest among stakeholders negatively affect ecotourism development.

- The optimized dynamic penalty-incentive method can obtain an ideal stable strategy.

- Optimized policy modes can coordinate interests and promote ecotourism development. 


\section{Declaration of interests}

$\bigotimes$ The authors declare that they have no known competing financial interests or personal relationships that could have appeared to influence the work reported in this paper.

$\square$ The authors declare the following financial interests/personal relationships which may be considered as potential competing interests: 